IZA DP No. 9597

Local Signals and the Returns to Foreign Education

Massimiliano Tani

December 2015 


\title{
Local Signals and the Returns to Foreign Education
}

\author{
Massimiliano Tani \\ UNSW Canberra \\ and IZA
}

\section{Discussion Paper No. 9597 \\ December 2015}

\author{
IZA \\ P.O. Box 7240 \\ 53072 Bonn \\ Germany \\ Phone: +49-228-3894-0 \\ Fax: +49-228-3894-180 \\ E-mail: iza@iza.org
}

\begin{abstract}
Any opinions expressed here are those of the author(s) and not those of IZA. Research published in this series may include views on policy, but the institute itself takes no institutional policy positions. The IZA research network is committed to the IZA Guiding Principles of Research Integrity.

The Institute for the Study of Labor (IZA) in Bonn is a local and virtual international research center and a place of communication between science, politics and business. IZA is an independent nonprofit organization supported by Deutsche Post Foundation. The center is associated with the University of Bonn and offers a stimulating research environment through its international network, workshops and conferences, data service, project support, research visits and doctoral program. IZA engages in (i) original and internationally competitive research in all fields of labor economics, (ii) development of policy concepts, and (iii) dissemination of research results and concepts to the interested public.
\end{abstract}

IZA Discussion Papers often represent preliminary work and are circulated to encourage discussion. Citation of such a paper should account for its provisional character. A revised version may be available directly from the author. 
IZA Discussion Paper No. 9597

December 2015

\section{ABSTRACT}

\section{Local Signals and the Returns to Foreign Education}

This paper exploits a quasi-experiment to shed light on whether the wage penalty experienced by migrants reflects poor schooling quality in the country of education or employers' discrimination in the host country. The quasi-experiment is the possibility for migrants to undertake an official assessment of their foreign qualifications, and remove the uncertainty surrounding the educational curriculum completed abroad. Data about the assessment can be used together with indicators of where education was completed to test empirically which determinant most affects the returns to foreign education. Since the assessment is a choice it is instrumented with a measure of relative distance between awareness of degrees awarded in the country of education and the host country. The analysis is based on the Longitudinal Survey of Immigrants to Australia. The results suggest that undertaking the assessment raises the returns of foreign education, offsetting the penalty for being educated abroad. The assessment's effect weakens over time, as employers observe migrants' productivity. The effect of where schooling is completed also trends upwards over time. These findings are consistent with the hypothesis of statistical discrimination due to the imperfect information about migrants' educational credentials. Adding a local signal appears to be effective in easing immigrants' economic assimilation and improve the international transferability of their human capital.

JEL Classification: $\quad \mathrm{J} 24, \mathrm{~J} 61, \mathrm{~J} 70$

Keywords: immigration, foreign education, statistical discrimination

Corresponding author:

Massimiliano Tani

School of Business

UNSW Canberra

Northcott Drive

Campbell ACT 2612

Australia

E-mail:m.tani@adfa.edu.au 


\section{Introduction}

There is common evidence that labour markets do not recognise foreign education in the same way as that acquired domestically (Chiswick, 1978) even when immigrants are selected on the basis of their human capital, as in Australia, Canada and New Zealand. The wage penalty associated to foreign schooling can be substantial (Sweetman, 2004; Chiswick and Miller, 2008), as is the probability of ending up in a job that requires a lower level of education than the one possessed (McGuinness, 2006; Green et al, 2007; Wald and Fang, 2008; Poot and Stillman, 2007; Chiswick and Miller, 2009).

Although the penalty decreases with time spent in the host country, the causes of its emergence have been attributed to two broad competing hypotheses. The first suggests that foreign education is less valuable than the one acquired domestically because it is of lower quality. Schooling in some countries of origin is poorly funded, delivered in overcrowded classrooms (Bratsberg and Terrell, 2002; Betts and Lofstrom, 2000), and associated with lesser outcomes in reading and mathematics literacy relative to what is reported for equivalent levels of education in the countries of destination (Sweetman, 2004; Chiswick and Miller, 2010).

The alternative hypothesis suggests that foreign education provides an obfuscated signal of productivity, particularly when acquired in countries that differ in language, institutions or culture from the home country. In such cases, host country employers overweigh group indicators of productivity rather than individual education, causing migrants to be 'statistically discriminated' (Farber and Gibbson, 1996; Altonji and Pierret, 2001; Lange, 2007). Over time, as employers observe migrants' productivity, the returns to foreign education increase but the catch up with native wages may be very slow. 
Determining which hypothesis is empirically supported is relevant because it carries different policy implications, including reliance on migration as an efficient mechanism to remove international imbalances across labour markets. However, providing an answer has been challenging as existing database hardly offer separate measures of where migrants are educated as well as host country employers' familiarity with it, thereby preventing the empirical identification of the two alternatives.

This paper addresses this problem by exploiting a quasi-experiment characterising migration to Australia, where immigrants have the possibility to gain an official assessment of their foreign qualification and its local equivalent from the Department of Immigration ${ }^{1}$. Data about the assessment can be used alongside information on where education was completed to determine the effect of each indicator on the returns to foreign education and test which of the two hypothesis is supported.

The assessment is available to individuals eligible for study or work holding post-secondary schooling lasting more than a year and awarded by a formal degree. There is no fee for the service, though there may be for translations or the use of agents, and the response turnaround is fast, lasting only a few weeks (normally 4-6). For prospective employers the assessment removes the uncertainty surrounding the educational curriculum completed abroad and acts as a reliable local signal of a migrant's human capital quality and productivity. Undertaking the assessment is however an individual choice likely to reflect unobserved characteristics that contribute to wage determination. Endogeneity arises from the fact that migrants understand that their degree's awareness may not be perfect in the eyes of host country employers. Some

\footnotetext{
${ }^{1}$ The objective of the Department of Immigration and Border Security (Overseas Qualification Unit) and its authorized agents is "to assist migrants to obtain recognition of their overseas gained skills and qualifications" especially with respect to "statements of educational comparison for qualifications obtained overseas; and information on where and how to obtain specific occupational assessments and which occupations have licensing and regulatory requirements.” (http://www.immi.gov.au/asri/os-qual-units.htm accessed 14 January 2014). Since the early 2000s the assessment of foreign qualifications is mandatory. An example of application is: http://www.training.qld.gov.au/resources/information/pdf/overseas-qualifications-assessment.pdf.
} 
migrants may hold internationally well-known degrees and may opt against adding an indicator of educational equivalence. Other migrants may feel the need to back up less known qualifications (in Australia) with a credible local signal to better their employment chances. Self-selection into undertaking the assessment may therefore mask unobserved educational before migration, ability and motivation. Using the assessment as a determinant of postmigration wages may over-estimate the true effect.

To overcome this issue and identify the causal effect of the assessment, the analysis uses an instrument proxying the informational cost of holding a less-known foreign degree. This is constructed using the difference between the worldwide ranks of the best-known university in the country of education and its Australian counterpart using data sourced from Webmetrics. Since 2004 this database publishes an annual world rank of more than five thousand universities located in virtually every country around the globe. The maintained hypothesis is that higher distance between top-ranked foreign and home university reflects lower awareness about foreign qualifications from that country in Australia, and stronger incentives for its degree holders to add a credible local signal. To reduce the possibility that the instrument merely reflects heterogeneity in educational quality across countries rather than an informational gap about foreign qualifications, the empirical analysis employs additional control indicators for the country of education (official language, institutional settings, and level of economic development).

The analysis is based on the Longitudinal Survey of Immigrants to Australia (LSIA ${ }^{2}$ ). This is a rich panel dataset focusing on the process of migration of two representative cohorts of immigrants in the mid- and late- 1990s. It contains several questions covering behaviours and expectations pre- and post-settlement including the country where the highest level of

\footnotetext{
${ }^{2}$ The LSIA was explicitly designed to exclude potential immigrants applying onshore, such as international students in Australia and New Zealand residents, who can freely settle in Australia.
} 
education was acquired and whether this was formally assessed. The panel spans over three (first cohort) and two waves (second cohort), respectively.

The empirical analysis is articulated in two steps. The first studies the wage penalty of foreign education and the effect of the assessment, if any, immediately after arrival. This is the time when employers' uncertainty about migrants' individual productivity is highest and when migrants are most unfamiliar with the workings of the host country's labour market. In addition, this is also the time when migrants acquire local signals that may determine subsequent career choices and the speed of their economic assimilation. This part of the analysis uses cross-sectional data from the first wave of both LSIA cohorts.

The second part of the analysis studies the evolution of migrants' wages, tracing the effect of the assessment over time, once employers actually observe migrants' productivity. Here the analysis applies panel data estimation techniques to all LSIA waves.

The results suggest that the local signal is effective in reducing the penalty for being educated abroad and its effect lasts over time. Migrants' foreign education also acquires more weight in determining their wage after settlement but only in few cases. These results are broadly in line with the predictions of the statistical discrimination hypothesis: employers are initially uncertain about the productivity signal of foreign education and consequently weigh the wage offers away from individual indicators of educational achievement. Adding the local signal reduces the penalty because it lowers the uncertainty surrounding the content of education acquired abroad.

This result contributes new insights to the formulation of migration policy as it shows that officially assessing foreign qualifications may improve the international transfer of human capital and the economic assimilation of highly qualified foreign-educated immigrants. 
The rest of the paper is organised as follows: Section 2 sets the literature background. Section 3 presents the data. Section 4 discusses the empirical strategy. Section 5 presents the results. Section 6 concludes.

\section{Literature}

The existence of a wage penalty associated with foreign education has emerged in various contexts. Early evidence starts with Chiswick (1978) in a study focusing on the economic assimilation of immigrants, in which he documents the lower returns to foreign education relative to schooling completed in the United States. Chiswick's evidence soon emerged in related US studies (Carliner, 1980; Friedberg, 1993; Schoemi, 1997) as well as analyses focusing on other destination countries, such as Canada (Baker and Benjamin, 1994; Schaafsma and Sweetman, 2001; Ferrer and Riddell, 2008), Australia (Beggs and Chapman, 1988; Chiswick and Miller, 2005), Spain (Sanroma’, Ramos and Simon, 2009) and Germany (Basilio and Bauer, 2010; Dustmann and Glitz, 2011). Though documenting the phenomenon, this literature does not explore the reasons behind the wage penalty of foreign education as its interest lies in the economic assimilation of immigrants and whether their earnings catch up with those of natives.

Separate strands of literature broadly interested in the characteristics of migrants' human capital have examined why their returns to education are lower when migrants complete their schooling abroad. The largest strand focuses on labour supply and attributes the lower returns to foreign schooling to the lower quality of migrants' human capital. By extension, this is viewed as the consequence of lower schooling quality in their home country. Inefficient delivery in education can arise from overcrowded classrooms and poorly paid teachers, as well as inadequate public investments in education (Betts and Lofstrom, 2000; Bratsberg and Terrell, 2002). The underlying idea is that a less efficient delivery of education slows the formation of human capital. Migrants educated in systematically less efficient systems 
receive lower returns to schooling than comparably educated people in the country of destination because they actually possess less human capital. Recent work using international data on student learning outcomes (OECD, 2010) supports that poor literacy and numeracy scores in many sending countries are positively related to the lower earnings of their emigrants, and vice-versa (Sweetman, 2004; Chiswick and Miller, 2010).

Differences in language and culture between places of origin and destination also explain the wage penalty of foreign education, as they reduce the international transferability of human capital (Chiswick and Miller, 1992; Dustmann, 1999; Isphording, 2014). Indeed, learning or perfecting the host country's language skills can substantially improve migrants' labour market outcomes. In general, investing in education post-migration raises the returns to schooling thanks to the additional education acquired in the host country and, importantly, a compounding effect due to the recovery of part of the human capital acquired pre-migration (Friedberg, 2001).

In contrast, studies focusing on labour demand attribute the penalty to foreign education to some kind of frictions. Notwithstanding the evidence of outright discrimination (Battu and Sloane, 1999), the underlying idea is that host country employers face an informational disadvantage when trying to assess the productivity signal of migrants’ foreign qualifications, particularly when these are acquired in internationally unknown institutions or countries unrecognised for the excellence of their education systems. In such cases, host country employers are likely to under-weigh migrants’ personal educational achievements, preferring to rely on group measures of productivity that over-weigh observable characteristics such as gender and race (Arrow, 1973; Phelps, 1972; Cain and Aigner, 1977; Lundberg and Startz, 1983), age (Altonji and Pierret, 2001), or height (Shen, 2015). Over time employers observe migrants' productivity and can reassess the importance of a migrant's foreign schooling away 
from group indicators, reducing statistical discrimination overall. The time required for this to occur, however, can be measured in years (Lange, 2007).

The closest study to this paper is Siniver (2011), who tests the statistical discrimination of immigrants' physicians in Israel by focusing on the exogenous introduction of a mandatory 'accuracy test' in 1999 for those who intend to work in this profession. By comparing the earnings' difference between natives and foreign physicians entering Israel pre- and post1999, Siniver finds evidence of statistical discrimination with statistically significantly higher earnings for those undertaking the test.

Determining whether lower returns to foreign schooling can be attributed to labour supply or demand carries out different policy implications with respect to the geographic scope of possible interventions (whether in the country of origin or destination), and the target group of possible intervention (migrants or employers).

By analysing which explanations of the wage penalty of foreign education is empirically most supported, if any, and offering a causal interpretation to the results through the use of an instrumental variable, this paper aims to shed lights on the relevance of imperfect transfers of human capital across borders and contribute to the discussion about which measures may enhance the utilisation of foreign-educated immigrants. Skilled migration has been rapidly increasing over the last decades, and migrants' under-use even in countries applying selective migration policies is both puzzling and threating to view migration as an efficient tool to alleviate excess labour supplies and skills shortages within and across national labour markets.

\section{Data}

The LSIA was commissioned in the 1990s to collect better information on the settlement of new immigrants than what was available through the census. The LSIA is based on a 
representative sample of $5 \%$ of permanent migrants from two successive cohorts ${ }^{3}$, and contains more than 300 questions. LSIA1 surveys migrants arrived between September 1993 and August 1995 and is composed of three waves collected between 4-6 months after settlement and up to 41 months afterwards. LSIA2 surveys immigrants arrived between September 1999 and August 2000 and contains two waves collected between 4-6 months after settlement and about a 15 months later ${ }^{4}$. Despite being a short panel, the LSIA captures valuable information about migrants' conditions prior to moving and during the initial stages of settlement. It is therefore an ideal database to study topics related to early stages of migration because it covers the period at the very outset of migrants' life cycle in the host country. An informative description of the LSIA is in Cobb-Clark (2001).

The LSIA has a number of limitations that affect the analysis, including that it neither covers temporary migrants like international students nor native Australians and New Zealanders the latter face no work restrictions if resettling in Australia. Comparisons can therefore be made only between different immigrant groups.

Another limitation of the LSIA is that higher education is truncated at Bachelors' level, and hence it is not possible to distinguish those completing an undergraduate degree from those completing Masters’ or PhD education.

To improve the common support between those undertaking the assessment (assessed group) and those not undertaking it (not-assessed), the sample is restricted to primary applicants in working age (20-65), holding a foreign tertiary or higher degree, and not changing their qualifications' assessment status between LSIA waves ${ }^{5}$. Additional restrictions include the removal of observations with missing wage data and information on the education-occupation

\footnotetext{
${ }^{3}$ The LSIA oversamples some groups of individuals notably on visa categories. The humanitarian (refugee) category is over-represented but the weights to recover population statistics are available in the database.

${ }^{4}$ A third cohort, LSIA3, was collected using a substantially reduced version of the questionnaire. These data are not suitable for the analysis carried out in this paper and are hence not used.

${ }^{5}$ A substantial proportion of migrants undertake the assessment in wave 2 or 3 of the LSIA. The analysis discussed in the main text excludes those changing their status vis-à-vis the local signal after the first wave.
} 
mismatch in the year before migration, which is used as a proxy for ability. As shown in Table 1, this data trimming reduces the working sample to 1,383 observations in the first wave of LSIA, of which 752 belong to LSIA1 and 631 to LSIA2.

\section{[Table 1]}

Table 2 reports the summary statistics for the working sample by assessment status. The first two columns report unconditional mean and standard deviation, respectively, for the assessed group. The next two columns report the equivalent statistics for the not-assessed group. The last two columns report differences between assessed and not-assessed groups and the tstatistics of the Kruskal-Wallis test of differences in means. Statistically significant differences at the $1 \%, 5 \%$, and $10 \%$ level are noted with the symbols *, **, and ***.

\section{[Table 2]}

Assessed and not-assessed groups are similar with respect to the country of origin $(63 \%$ are born in an English-speaking country and about $40 \%$ in a member of the Commonwealth) and post-migration residential choices, with three quarters of migrants settling in or around Australia's two main cities. They also share demographic characteristics like age, gender composition (about a third are women), and marital status ( $60 \%$ are married). They have in common many post-migration occupational characteristics like a very low preference for selfemployment ( 2\%) and part-time work (13.5\%), and a high likelihood of managerial ( 70\%) or professional ( 15\%) occupations. About $40 \%$ of those in the assessed and $35 \%$ in the notassessed group work in a licensed occupation ${ }^{6}$, underlying the background as professionals.

\footnotetext{
${ }^{6}$ Finding which occupation requires a licence is not feasible at this stage, as Australia does not have a national system of licensed occupations. These are managed at a State level. The Council of Australian Governments (COAG) began discussions to introduce a national occupational licensing system for certain occupations in 2008. The aim was to remove "duplicate and inconsistent regulation for specific occupations between states and territories”. The proposed regulatory change however faced substantial opposition by States and professional associations, and was abandoned in 2013, following a change in federal government. For more information, see http://www.coag.gov.au/node/516 (accessed 26 December 2014). Nowadays, licensing requirements are explicitly reported in the description of some occupations, such as those in the medical profession. However, the description of several other professions only highlights that a licence "may be required", implying different regulations based on the type and location where a profession is carried out. I use this broader definition to
} 
Migrants in both groups possess high host country language skills, though the incidence of using English to respond to the LSIA interview is slightly higher for the assessed (97.1\% vs. $96.5 \%)$

Both groups instead are statistically significantly different with respect to fertility choices (the assessed are more likely to live with young children: $58.9 \%$ vs. $47.9 \%$ ), the type of visa obtained for settling in Australia, where they completed their education, and the wage received shortly after settlement.

With respect to visa categories, the assessed group is overwhelmingly admitted through the point system, which comprises the concessional family and skilled independent visa categories. These are predominantly economic migrants with high prospects of immediate employability but no host country support from family, employers or local institutions. In contrast, the not-assessed group includes a more heterogeneous group of migrants that settles to be reunited with family members, escape conditions at home (humanitarian visa), and fill skills shortages (employer sponsorship).

Immigrants in both LSIA1 and LSIA2 complete their tertiary education in various geographic regions. Those using English as the official language (UK/Ireland, US, Canada, South Africa and several other nations in Asia and Africa) account for two thirds of the observations. The next most common region is East/South East Asia with about 20\% of the observations, followed by South Asia and the Pacific islands ex-New Zealand with about 10\%. Migrants completing university in Europe account for about $15 \%$ of the observations, almost equally split between the then 15 countries of the European Union or European Economic Area, and central European countries, including Russia and the former Eastern Europe.

construct a dummy variable equal to one for occupations that do or may require licensing, and zero otherwise. Occupations in LSIA are reported at a 4-digit ASCO code. This however is not sufficient to know exactly if the occupation is subject to licencing, as more precise information is available only at 6-digit level. The consequent measurement error attributes licensing to occupations that may not and hence contributes to the attenuation bias. The estimates obtained therefore measure the lower bound. 
In the empirical analysis these countries of education are aggregated in three similarly-sized groups: Northwest Europe and North America, which gather high-income countries (the reference group), Asia, and the rest of the world. As highlighted in Table 1 there are substantial differences in where education was completed between both groups. Undertaking the assessment is less common amongst those graduating in Northwest Europe and North America as well as Asia relative to graduates from the rest of the world.

With reference to migrants' foreign qualifications, about $40 \%$ of the sample undertakes the assessment by the time of the first LSIA wave (472 on a total of 1,383 migrants). Figure 1 presents the uptake rates by geographic region of education.

[Figure 1]

There is significant regional variation, with substantially lower rates for those graduating from an English-speaking country and Western Europe. The highest uptake rates occur amongst those graduating in South Asia/Oceania. This region includes several countries sharing common historical and institutional ties with Australia as evidenced by membership to the Commonwealth. High uptake rates of the assessment occur also amongst those graduating from Russia and Eastern Europe.

Table 2 also reports the unconditional mean of the dependent variable, the logarithm of gross weekly wages ${ }^{7}$. On average, this is slightly lower for the assessed group (6.459 vs. 6.497), suggesting the possible influence of negative selection. Care is hence necessary to identify the effect of the assessment from institutional settings and selection mechanisms that influence migrants' wages in the host country. Figure 2 shows the distribution of the dependent variable by assessment status across the nine regions of education based on the 1-digit geographic grouping used by the Australian Bureau of Statistics (ASSCC code).

[Figure 2]

\footnotetext{
${ }^{7}$ Wage data in the LSIA are reported as categories. I hence use the mid-point of each interval, and apply a 1.4 multiple to the highest category.
} 
For most non-English speaking places of origin the wage distribution of the assessed is to the right of the corresponding distribution for the not-assessed group, implying that undertaking the assessment has a positive effect on wages. However, Figure 2 also shows that the assessment seems to have a negative effect on the wage distribution of those completing their education in North America and Northwest Europe.

Using a geographic grouping based on the official language used of the countries of education does not alter this result (Figure A1). No meaningful difference arises when the logarithm of the hourly wage is used as a dependent variable (Figure A2). As undertaking the assessment is unlikely to reflect irrationality such choice may reflect the need to recognise qualifications from less known institutions to access occupations subject to licensing, though there is only weak evidence of a link between these two indicators in the data.

Table 3 reports the attrition rates of LSIA1 and LSIA2 with respect to the sample of 20-65 years old and the working sample to highlight the possible over/under-representation of assessed across waves causing distortions in the analysis of panel data. On average $14.3 \%$ of LSIA1 and $17.2 \%$ of LSIA2 respondents in the first wave do not continue with the survey. The corresponding figures amongst the assessed in the working sample are $13.1 \%$ for LSIA1 and $15.1 \%$ for LSIA, respectively. Those proportions do not appear out of line with the overall sample attrition.

\section{Empirical strategy}

\subsection{Estimation}

The analysis comprises two parts. The first focuses on the effect of the treatment on migrants' wages in the months just after settlement. This is the crucial period where a new lifecycle in the host country begins and migrants enter its labour market. This analysis applies TwoStage-Least-Squares estimation (2SLS) on cross-sectional data from the first wave of LSIA using the functional form: 


$$
w_{i j}=\beta_{0}+Z_{i j h} \gamma_{h}+\beta_{1} \tilde{X}_{i j}+\beta_{2} \widetilde{D}_{i j}+\tau_{i j}
$$

where $\tau_{i j}$ is an i.i.d. error term and $\beta_{0}, \beta_{1}, \beta_{2}$, and $\gamma$ are parameters to be estimated. In particular:

$w_{i j}$ is the logarithm of the gross weekly wage of individual $i$ graduating in region $j$;

$Z_{i j h}$ is a set of $h$ exogenous covariates that include demographic, visa and labour market indicators as well as controls for the institutional settings in the countries of education and birth $^{8}$.

$\tilde{X}_{i j}$ is a set of two dummy variables of the regions where migrants completed their highest level of education. These are Asia and the Rest of the World. The reference group includes Northwest Europe and North America, hence a set of high-income countries. These are interacted with dummy variables describing age groups to account for heterogeneity within each region of education ${ }^{9}$. In a more restrictive specification a group of nine regions is used ${ }^{10}$, each interacted with age groups.

Although education completed in an English-speaking country constitutes a common reference group in the literature (Kler, 2007; Chiswick and Miller, 1995), doing so removes the possibility to distinguish the place of education, which proxies for schooling quality, from other country of education-specific wage determinants such as language and institutional

\footnotetext{
${ }^{8}$ Demographic characteristics include experience and experience squared, gender, marital status, whether there are resident children in the household, the cohort, and whether the LSIA interview was carried out in English (as recorded by the interviewer). Labour market characteristics include whether the state of residence in Australia, if self-employed, and if current work is part-time (less than 35 hours per week), and the inverse mills ratio controlling for selection into employment. Visa characteristics include the main visa used for admission and its interactions with cohort, to control for the tightening of admission policy between LSIA1 and LSIA2. The institutional controls for the country of education include whether English is used as a main language and the level of GDP per capita. Those focusing on the country of birth include dummy variables controlling whether the former home country uses English as a main language, whether it is part of the Commonwealth, income inequality in or around 1998 (Gini coefficient), sourced from the United Nations World Income Inequality Database (WIID - https://www.wider.unu.edu/data), and the share of immigrants from that country in Australia based on the 2001 Census (Australian Bureau of Statistics, 2015, publication 3412.0, Table 3.1).

${ }^{9}$ The groups cover age 20-27; 28-32; 33-39; and 40-65 respectively; this grouping results in similar number of observations in each category.

${ }^{10}$ North West Europe, North America, South and East Europe, Middle East and North Africa, East Asia, South East Asia, South Asia, South America, Pacific island, and Africa.
} 
similarities due to perfect multicollinearity. The aggregation used is the result of choices reflecting on the one side geographic areas displaying heterogeneous values for the instrument, and on the other no perfect correlation with the use of English as the main language of the country of education.

$\widetilde{D}_{i j}$ is the instrumented endogenous dummy variable indicating if the migrant's foreign qualifications have been assessed, as discussed in section 4.2.

The second part of the empirical analysis focuses on the panel dimension of the LSIA to study whether the returns to foreign human capital rise as employers observe migrants' productivity, and applies the statistical model:

$$
w_{i j r}=a_{0}+Z_{i j h r} A_{h}+a_{1} \tilde{X}_{i j r}+a_{2} \tilde{X}_{i j r} t+a_{3} \widetilde{D}_{i j r}+a_{4} \widetilde{D}_{i j r} t+a_{5} t+\theta_{i j r}
$$

where $r$ represents the wave of LSIA panel, $t$ is the time since the first interview (in days), the covariates $Z_{i j h r}, \tilde{X}_{i j r}$ and $\widetilde{D}_{i j r}$ are as previously described, and $a_{0}, \ldots, a_{5}$ and $A$ are sets of parameters to be estimated.

The composite error term $\theta_{i j r}=\delta_{j i}+\eta_{i j r}$ contains an unobserved time-invariant individual component $\delta_{i j}$, which is removed when panel estimation techniques are applied, and an i.i.d. error term $\eta_{i j r}$. Employers' learning occurs when the weight of migrants' individual education before migrating increases over time whilst that of the signal diminishes. This is consistent with a positive $a_{2}$ and a negative or nil $a_{4}$.

Estimation of (2) is performed using panel data random effects, as the variable of interest is time-invariant and cannot be identified if the regression is carried out using the fixed effects estimator. The random effects estimator, however, relies on the assumption of orthogonality between $\delta_{j i}$ and the covariates $Z_{i j h r}, \widetilde{X}_{i j r}$ and $\widetilde{D}_{i j r}$. Two random-effects estimators are applied, differing in the construction of instruments. The first method uses only the exogenous variables after they have been passed through the feasible Generalised Least Square (GLS) 
transform to remove the time-invariant unobserved heterogeneity. The second method uses a combination of both within and between transforms to generate a wider set of instruments. Baltagi and Liu (2009) show that in finite panels the second method yields more efficient estimates, though these instruments may be redundant as the size of the panel increases.

Since the orthogonality condition between $\delta_{j i}$ and the covariates $Z_{i j h r}, \widetilde{X}_{i j r}$ and $\widetilde{D}_{i j r}$ is often unrealistic, model (2) is also estimated applying an alternative panel data estimator, the Hausman and Taylor estimator ${ }^{11}$, which allows some of the regressors to be correlated with the individual effect $\delta_{i j}$. Baltagi et al. (2003) show that when the panel is short (less than five years) and some of the regressors are correlated with $\delta_{i j}$ the random effect estimator is biased and leads to misleading inference. In such case the preferred option is the Hausman-Taylor estimator.

\subsection{Identification}

The LSIA contains information on both place of education and whether migrants have undertaken the assessment of their foreign qualifications, thereby offering indicators for the quality (place of education) and host country employers' awareness of foreign education (whether or not assessed in Australia). The endogeneity of the assessment indicator arises from the likely non-random distribution of the immigrant population undertaking it, particularly amongst migrants with less known qualifications but high ability and motivation, and those with work experience in countries with institutions and labour market similar to Australia's, who may better understand the effect of the assessment on the probability to get a (desired) job. Using this measure may result in biased estimates of the assessment's actual effect.

\footnotetext{
${ }^{11}$ This estimator uses both the between and within variation of the strictly exogenous variables as instruments. More specifically, the individual means of the strictly exogenous regressors are used as instruments for the time invariant regressors that are correlated with the individual effects. See Hausman and Taylor (1981).
} 
To identify the incentive to undertake the assessment I use exogenous variation in the relative awareness of a degree obtained in the country of education relative to Australia. In particular, I use the median level of awareness to generate a dummy variable instrumenting the assessment. The maintained hypothesis is that higher unawareness (i.e. above-median distance) underpins a higher probability that a prospective Australian employer will not offer a wage related to migrants' individual educational qualifications but to other observable characteristics, like gender or age. Higher unawareness implies therefore a higher cost of not undertaking the assessment, and vice-versa ${ }^{12}$ (relevance condition for IV).

The instrument is constructed in two steps using data from the Webmetrics database ${ }^{13}$, which since 2004 ranks on an annual basis more than 5,000 universities across the world. The characteristic of 'best ranked' is obtained by Webmetrics using the number of citations in the top international $10 \%$ scientific journals by field of study, which are then combined in an overall rank at university level. In the first step, the difference between the best-ranked university in the country of highest education and the best-ranked one in Australia is calculated. The second step involves the derivation of the instrument using above- or belowmedian differences ${ }^{14}$.

Instrumenting an endogenous choice with an opportunity cost measure such as distance is not uncommon in the literature, as examples related to schooling (Card, 1995) and migration

\footnotetext{
12 The basic intuition of this approach is supported by a regression similar in spirit to Card (1995): the probability of undertaking the assessment is always higher in countries with relative rank above the median distance in than in those below, and the difference grows by quartile.

${ }^{13}$ The ranking is based on the university scientific output that is in the $10 \%$ most cited papers in their respective scientific fields, and is sourced from the Webmetrics database (www.webmetrics.info/en), which accounts for about 5,200 universities around the world. Carrying out the analysis using the country of last residence rather than the country of highest education does not modify the results.

${ }^{14}$ The median raw difference across all countries where migrants completed their university is +134 . As a result, a degree gained in the United States, whose best university (worldwide raw rank: 1) is ranked ahead of Australia's (34), is by assumption deemed to have no informational disadvantage from an Australian viewpoint, and its degree holders would have no incentive to add the local signal. Conversely, degrees from, say, Romania (793) or Peru (1962) face substantial informational disadvantage in Australia, creating strong incentives for graduates from these countries to undertake the assessment. Using a more granular instrument (4 categories) yields similar results to those obtained using the median, as is later discussed. Using country-specific variation results in similar results to those obtained using the median with respect to the sign but have no statistical significance.
} 
(McKenzie and Rapoport, 2010) show. However, as emphasised by Heckman (1997), the validity of using an instrument to evaluate a treatment relies on the strong assumption that participants do not make their participating decision based on "unobserved (by the analyst) components of program gains... [This] implies a strong form of ignorance or irrationality about unobserved components of gain on the part of the people being studied. It also implies that persons do not have private information that is useful in forecasting the gains that they use in making their decisions but that is not available to the analyst” (p.460).

While this is probably true in several cases, the possibility that people do not exactly know the gains of undertaking the assessment beyond what is observed by a researcher (like entry into certain occupations) does not appear unlikely in the case of international migration. Recent migrants may have only a generic understanding of the new institutional settings in which they find themselves at the beginning of their life in the host country. Such understanding may in turn reflect general information provided by the Department of Immigration or public domains like the worldwide web (individual experiences of friends and relatives will be separately controlled for). It is not unrealistic to support that migrants take the assessment thinking that it may turn out to be useful without exactly knowing how useful it will actually be (independence condition for IV).

This hypothesis is supported by the fact that migrants with no pre-existing network of family and friends in Australia, from whom to source private information, do not have a higher probability to undertake the assessment than those who do not. This outcome is the result of a regression of undertaking the assessment on the interaction between the instrumental variable and (i) the visa group and (ii) the existence of relatives living in Australia, controlling for other characteristics ${ }^{15}$. This result supports the legitimacy of the instrument used.

\footnotetext{
${ }^{15}$ The LSIA contains information on the number of relatives living in Australia but not with the migrant and the visa category, which indicates whether a migrant has local support from family (family reunification and concessional family visa), employers (employer nomination visa), or the government (humanitarian visa).
} 
Notwithstanding that the relative distance between top ranked universities in Australia and the country of education might be a suitable proxy of the opportunity cost of holding an unknown foreign degree, it is important that the variation of the IV reflects imperfect information about foreign qualifications rather than other characteristics of the countries of education which may also affect migrants’ wages, incouding migrants’ self-selection based on the country of origin. If the assessment is more prevalent amongst migrants of countries with certain characteristics, such as a low level of economic development, then omitting this variable causes the IV estimator to be biased. The severity of this bias reflects the strength and sign of the correlation between the instrument (which now absorbs the effect of the omitted variable) and migrants' wages. To prevent this possibility the empirical analysis includes additional controls for the level of economic development of the country of education (logarithm of GDP per capita) and whether English is an official language, though not necessarily the primary one ${ }^{16}$ (Belot and Hatton, 2012; Bertoli and Rapoport, 2015).

In addition, to limit the possibility that the instrument captures various degrees of migrants' self-selection associated with the skill distribution in the countries of origin and pre-existing informational channels between these and Australia, the inequality of income distribution in the country of birth and the share of migrants in Australia who were born in the same country of birth are also included in the empirical specification (Montgomery, 1991; Munshi, 2003; Ioannides and Loury, 2004). As further indicator of individual ability, the robustness check analysis includes a dummy variable capturing migrants' excess schooling (over-education) in the last job before settlement in Australia.

Table 4 reports the estimates of the first stage regression. The top row shows the strong positive link between undertaking the assessment and the dummy IV. Obtaining the local

\footnotetext{
${ }^{16}$ A number of countries use English as one of their official languages, though the majority of the population may actually speak another idiom. The list used to define this dummy variable is https://en.wikipedia.org/wiki/List_of_territorial_entities_where_English_is_an_official_language.
} 
signal is substantially more likely if the relative distance between the highest ranked university in Australia and in the place of education is above the median. The estimate is statistically significant at the $1 \%$ level of significance, with an F-test of 58.62, which is well above the suggested benchmark of 10 (Angrist and Pischke, 2008).

Undertaking the assessment is statistically significantly negatively linked to where education is completed relative to Northwest Europe and North America, to the official language of the country of education and its level of economic development. This result supports adding these variables in the empirical estimation as their omission would negatively bias the estimated effect of the treatment, as will be further discussed in section 5.1. Additional controls for migrants' self-selection are also affecting the probability of undertaking the assessment, both positively (if the country of birth shares institutional links with the host country or has high income inequality implying that emigrants may be highly skilled) and negatively (being born in a country using English as the main language). Controls for these sources of variation are also included in the empirical analysis.

Other variables that affect the probability of undertaking the assessment are the visa class and the migrant's knowledge of English. The first stage results show that those admitted under the point system are more likely to acquire the local signal. These are economic migrants selected on the basis of their educational qualifications as well as young age and knoweldge of English. Carrying out the LSIA interview in English implies an objectively good command of the host country language (the question is answered by interviewers), and a lower opportunity cost in undertaking the assessment.

Table 4 also reveals that interacting the region of education with age groups yields estimates that are no different from zero, implying that time since graduation within regions of education appears to have no bearing on the probability of undertaking the assessment. 
Similar results are obtained when a more granular set of regions of education is used, each interacted with the three broad age groups, and when the instrument is described by a 4category (rather than a 2-category) indicator.

\section{Results}

\subsection{Cross-sectional analysis}

Table 5 reports the estimates of the wage equation based on model (1) obtained by OLS and 2SLS, respectively. There are two specifications for each regression, depending on whether the specification includes occupational fixed effects. Their inclusion enhances the common support between assessed and not-assessed group, and strengthens the results that are discussed below. The other set of controls for each regression include demographics and labour market characteristics, visa category and interactions with cohort, and whether the migrant was over-educated in the last job before migrating.

Only the key explanatory variables referring to the assessment and where tertiary education was completed (proxying for schooling quality) are displayed in Table 5. In particular, the effect of the assessment is reported in the first row. Starting with the first two columns, the estimated coefficient in the OLS regression is no different from zero, supporting that undertaking the assessment has no effect on wage determination. Lack of a significant effect from the assessment using the LSIA has been noted before (Kler, 2005), but as discussed this may arise from the endogeneity of the choice of obtaining this signal ${ }^{17}$. In particular, the bias towards zero reflects offsetting effects between those educated in Northwest Europe and North America, who earn a lower wage then those not undertaking the assessment, and those completing their education elsewhere, who receive a higher wage if they undertake the assessment (see also Figure 2).

\footnotetext{
${ }^{17}$ The results of endogeneity tests are reported in Table A1 in the Appendix.
} 
In the 2SLS estimation (next two columns) the effect of the assessment is positive albeit statistically significantly different from zero only at the $10 \%$ level, or $5 \%$ when occupational fixed effects are included.

The middle part of Table 5 shows the effect of schooling quality on wages. In the case of both OLS specifications, completing a degree from Latin America, Africa or the Pacific islands ('Rest of the world') results in substantially lower wages shortly after settlement than when qualifications are gained in Northwest Europe or North America. The 2SLS estimation confirms the wage penalty of being educated in countries other than the reference group, though such penalty is statistically different from zero only for degrees acquired in the rest of the world. Those obtained in Asia are penalised, but in the estimation by 2SLS the effect is statistically no different from zero. Table 6 reports 2SLS estimates of the assessment when control variables are introduced incrementally, to show the stability of this result.

Table 7 presents the effect of the treatment across different groups of migrants exploring the heterogeneity across genders, job status before migration, cohort, and type of work in Australia. Each case reported is based on model (1) estimated by 2SLS excluding occupational fixed effects. The instrument performs well in each case, with the F-test from the first stage regression always above the threshold of 10 suggested in IV estimation except for the case of being born in a Commonwealth member state due to the high collinearity with the use of English as language of education. The analysis reveals that the positive effect of the assessment is larger for women, for being born in a member state of the Commonwealth, carrying out a non-licensed occupation in Australia, and having migrated in the more recent cohort, after immigration policy was tightened.

Men are on average more likely to undertake the assessment, but the weaker effect of the signal may reflect their higher dispersion across occupations vis-à-vis professional jobs 
whose practice is less varied internationally and requires specific local knowledge when carried out, as in nursing or medicine, where women tend to concentrate. On average women receive a higher wage than men, but this is largely driven by engagement in part-time occupations. Unlike men, women are not penalised for where they complete their tertiary education.

Finding that the assessment effect is statistically stronger for migrants born in a member state of the Commonwealth but not elsewhere shows that the informational disadvantage is felt amongst those closer to the reference group along some dimension, like mastery in English or exposure to institutional settings similar to Australia's, but hold degrees from countries that are internationally unrecognised for the prominence of their tertiary institutions. This does not occur amongst those born outside the Commonwealth, for whom the local signal may appear ineffective in alleviating educational and other differences with the reference group. Part of this outcome reflects that many non-Commonwealth migrants enter manual jobs upon settlement, despite their tertiary education, possibly due to financial constraints (this group of migrants brings to Australia only half of the funds brought by those born in a Commonwealth member state).

Undertaking the assessment does not reflect differences between occupations subject/not subject to licensing. Non-licensed jobs tend to have lower barriers to entry than jobs whose practice is restricted by professional associations, but seem to pay much higher wages. Competition for non-licensed jobs may provide incentives to gain additional signals of productivity.

\subsection{Panel analysis}

Table 8 reports the wage penalty based on regressions performed on equation (2) when migrants' employer do not change across waves and without occupational fixed effects. Two 
alternative approaches are followed in the estimation of this equation. The first views the individual fixed effect as a random variable and uses the random effect estimator assuming orthogonality between the instrument and the error term. This panel random effect estimator is implemented in two different specifications, depending on the construction of the instruments. In the first instance, which is labeled Panel RE and reported in the first column, there is a single set of instruments obtained by passing each exogenous variable in the feasible GLS transform. The more complex version of panel random effect estimation uses a higher number of instruments that include the feasible GLS transform multiplied by time and the group means of each exogenous variable ${ }^{18}$. This version is labelled Panel RE Baltagi and is reported in the middle column of Table 8.

The second approach in panel estimation allows the endogenous variable to correlate with some of the exogenous regressors. Under this assumption the endogenous decision can be instrumented with the lagged set of orthogonal covariates in the regression, effectively performing fixed effect panel data estimation without eliminating time-invariant regressors and without recourse to exclusion restrictions. The results are reported in the right column of Table 8. This specification is preferred due to the less restrictive assumptions on which it relies.

The first row in Table 8 shows the effect of obtaining the local signal on wages over time. The effect is positive and statistically significantly different from zero in each model, confirming that gaining a local signal helps wage determination also once time-invariant individual heterogeneity is controlled for. As was shown by Table 3, the attrition rate amongst those undertaking the assessment in the first wave is not very different from the overall attrition in the LSIA, implying that sample selection across waves is unlikely to drive these results. The magnitude of the estimate in both Panel RE and Panel RE Baltagi is close

\footnotetext{
${ }^{18}$ for discussion and derivation see http://www.stata.com/manuals13/xtxtivreg.pdf
} 
to that obtained in the cross-section 2SLS of about 0.4. This is similar to the magnitude of the effect based on the Hausman-Taylor estimator, implying a limited correlation between the treatment indicator and the other covariates.

The second row of Table 8 shows the effect of the local signal over time. Here the estimate is always statistically different from zero, suggesting that the signal is useful at entry in the labour market of the host country, and at least in the short time span of the LSIA there is a compounding effect. Host country employers hence appear to attribute relevance to the signal both when migrants are hired and in subsequent periods. This may underpin an initial reluctance amongst employers in immediately recognising the information contained in the local signal, and a preference for a gradual approach in rewarding those who have undertaken the assessment that may be explained by industry structure or type of employer (unfortunately both not recorded in the LSIA).

All random effect estimators support that there is a strong wage penalty for those holding degrees from countries that are less economically developed than the reference group or where migration to Australia is a relatively new phenomenon. As already emerged in the cross sectional analysis the penalty is higher for those graduating from Latin America, Africa and the Pacific islands. By the time of the second or third wave of the LSIA, employers actually observe migrants’ productivity but the wage penalty does neither appear to reduce substantially nor human capital acquired abroad on average appears to be recovered by migrants, though the positive sign of the interaction terms with time since migration suggests an upward trend. This result is consistent with the finding that it takes time (years) for employers to learn the productivity of their employees and to recognise it in the determination of wages (Lange, 2007). Even by the time of the third LSIA wave, migrants have been in Australia for a short time (three years at most). 
Table 9 extends the analysis to various sub-groups using the Hausman-Taylor estimator. The result supports that the local signal improves wages and its effect continues across the short period covered by the LSIA. Including occupational fixed effects does not modify this conclusion. Few cases are worth highlighting, covering the case when migrants change employer, when they enter jobs requiring a license, and heterogeneity in the region of birth.

When migrants change employer, the direct effect of the local signal no longer differs from zero though its relevance over time remains positive and statistically significant. This is consistent with the hypothesis that the local signal has still value in determining wages set by the new employers, perhaps because migrants' work experience in Australia is too short to be entirely relied upon at the time of the change or because employers can afford to delay the recognition of migrants' human capital possibly due to limited competition within the industry in which they operate.

When data covering same and new employers over time there is no longer a penalty on where migrants acquired their qualifications, and the signs of the estimates support the predictions of the statistical discrimination model: a reduction in the penalty of foreign education and a corresponding increase of the returns to education acquired pre-migration. The estimates however are no different from zero.

Table 9 also suggests that licensing acts as a selection mechanism that partly captures the effect of the local signal: undertaking the assessment has a positive effect on wages in both licensed and non-licensed occupation, but its effects over time and the penalty for tertiary education acquired outside of Europe, Asia and North America are no longer statistically significant in the case of licensed jobs.

The estimates support that migrants working in licensed occupations receive lower average wages than those working in non-licensed jobs, implying that these migrants are assigned to 
relatively junior positions. In contrast, high competition for non-licensed jobs may underpin both the presence of significant penalties to education completed in countries that are relatively distant from Australia in terms of top university ranking, and the persistence of the effects of the local signal over time.

Within the regions of birth, controlling for time-invariant individual heterogeneity absorbs some of the effect of the local signal, though this is no longer different from zero only in the case of those born within the Commonwealth. Those migrants experience a wage penalty, especially if they graduated from the rest of the world, though they are able to recover some of the human capital acquired pre-migration over time. In the case of immigrants with a nonEnglish background, undertaking the assessment always raises wages, compensating for the penalty to being educated outside the reference group.

\section{Conclusions}

The well-known fact that migrants suffer lower returns to education when this is obtained in a different country from that of destination arises also in Australia for tertiary-educated migrants.

As labour markets outcomes tend to persist, starting with 'the right foot' in the host country's can not only improve migrants’ personal returns to human capital but also their spill-over effects on the host society via higher wages hence consumption, taxable income and wellbeing.

Wages substantial improve when a local signal is added to educational qualifications obtained abroad, in line with the hypothesis that Australian employers may statistically discriminate migrants. On average a migrant undertaking the assessment can enjoy a $40 \%$ increase in gross weekly wages. This is a huge effect, though the low number of observations does not enable one to fully take into account the effect of worked hours and more granular occupational groupings, which probably concur in generating such estimate. 
The estimated increase of an average wage shortly after settlement is in the order of 110 Australian dollars (A\$) per week per migrant at constant 1995 A\$. Given this benefits Australia's government decision to make the assessment mandatory in the early 2000s appears well placed.

However, one may wonder why each migrant did not undertake the assessment at the time this was a choice given the large wage gain found. One possible explanation is that only the most able migrants felt the need to undertake the assessment. Less able migrants would have instead benefited from receiving wages based on group rather than individual indicators of productivity with no need to undertake the local signal. The assessment however was not a test of ability but a document issued by a credible local institution reporting the local educational equivalent of a foreign degree. Its aim is to reduce the uncertainty surrounding qualifications obtained abroad. Using an indicator of individual ability using over-education in the last job prior to migration does not modify the results discussed.

A second possible explanation is migrants' decision to undergo career changes for which previous educational signals were not seen as important. A number of migrants switched occupation between their last job in the country of origin and Australia and this did not result in lower happiness about labour market outcomes or intentions to change occupation, as emerging from additional subjective information collected by the LSIA. For some migrants job-switching does not appear to have been a forced choice. Changing country of residence may underpin a change in the type of life one carried out, or a shift of focus towards the wellbeing and success of one's children rather than one's own.

A third possible explanation is that migrants may initially join the labour market to learn its workings and the host country's institutional settings to better gauge later on where working opportunities lie. This would delay undertaking the assessment until later on and while there 
is evidence of it in the LSIA the number of observations is limited to carry out a quantitative analysis.

Notwithstanding these interpretations, the analysis discussed supports that foreign education is penalized, but that adding a local signal to qualifications obtained abroad can significantly reduce that penalty. This result has relevant policy implications, as the issue of imperfect international transferability of human capital and its reduction with time spent in the host country have been usually addressed with a lasses-faire approach relying on the efficiency of market forces in eventually recognizing individual productivity. This is however a suboptimal outcome. Migrants' under-use in the country of destination may cause loss of earnings and taxable income. Migrants may also remit lower amounts, reducing the potential benefits of emigration for countries of origin and families left behind. More generally, the penalty to foreign education raises questions about the effectiveness of migration as a tool to reduce international imbalances across national labour markets

This paper nevertheless shows that assessing foreign qualifications through a credible local authority may be an effective mechanism to fasten migrants' human capital transfer into the host country. Such measure can benefit migrants and the host society alike via faster economic assimilation and better utilization of the skills acquired elsewhere. As skilled migration keeps rising and countries increasingly consider following the model of those which have introduced selective immigration policies, the paper argues that time is ripe to focus also on how to migrants' foreign education can be quickly added to the host country's stock of human capital. 


\section{References}

Aigner, D. J., and G.G. Cain, (1977). "Statistical theories of discrimination in labor markets". Industrial and Labor Relations Review: 175-187.

Altinok, N., Diebolt, C., and J.L. Demeulemeester (2014). “A new international database on education quality: 1965-2010”. Applied Economics, 46(11): 1212-1247.

Altonji, J. and C. Pierret (2001). "Employer learning and statistical discrimination”. The Quarterly Journal of Economics, 116(1): 313-350

Angrist, J. D., and J.S. Pischke (2008). Mostly harmless econometrics: An empiricist's companion. Princeton University Press.

Arcidiacono,P., Bayer, P., and A. Hizmo (2010). "Beyond signaling and human capital: Education and the revelation of ability". American Economic Journal: Applied Economics 2(4): 76-104.

Arrow, K. (1973). “The theory of discrimination”. Discrimination in Labor Markets, 3(10): 3-33.

Artuc, E., Docquier, F., Özden, Ç., and C. Parsons (2015). “A global assessment of human capital mobility: the role of non-OECD destinations”. World Development, 65: 6-26.

Australian Bureau of Statistics (2006). ANZSCO: Australian and New Zealand Standard Classification of Occupations. Australian Bureau of Statistics/Statistics New Zealand. http://www.ausstats.abs.gov.au/ausstats/subscriber.nsf/0/B4B626DEB4A0C558CA2571E600 092D5A/\$File/12200_2006.pdf

Balsa, A. I., and T.G. McGuire (2001). "Statistical discrimination in health care”. Journal of Health Economics, 20(6): 881-907.

Baltagi, B. and L. Liu (2009). "A Note on the Application of EC2SLS and EC3SLS Estimators in Panel Data Models". Syracuse University: Center for Policy Research. Paper 50. http://surface.syr.edu/cpr/50

Baltagi, B., Bresson, G. and A. Pirotte (2003). "Fixed effects, random effects or HausmanTaylor?: A pretest estimator”. Economics Letters, 79(3): 361-369.

Basilio, L., and T.K. Bauer (2010). Transferability of Human Capital and Immigrant Assimilation-An Analysis for Germany. Ruhr Economic Paper, 164.

Battu, H. and P.J. Sloane (2004). "Over-education and ethnic minorities in Britain”. The Manchester School, 72: 535-559.

Baum, C.F., Schaffer, M.E., and S. Stillman (2010). ivreg2: Stata module for extended instrumental variables/2SLS, GMM and AC/HAC, LIML and k-class regression. http://ideas.repec.org/c/boc/bocode/s425401.html 
Belot, M. V., and Hatton, T. J. (2012). "Immigrant Selection in the OECD”. The Scandinavian Journal of Economics, 114(4): 1105-1128.

Bertoli, S., and Rapoport, H. (2015). "Heaven's Swing Door: Endogenous Skills, Migration Networks, and the Effectiveness of Quality-Selective Immigration Policies". The Scandinavian Journal of Economics, 117(2): 565-591.

Bloom, D.E., G. Grenier and M. Gunderson (1995). "The changing labour market position of Canadian immigrants”. The Canadian Journal of Economics, 28: 987-1005.

Bordón, P., and B. Braga (2013). Employer Learning, Statistical Discrimination and University Prestige. Unpublished paper, University of Wisconsin-Madison.

Bun, M. J., and T.D. Harrison (2014). OLS and IV estimation of regression models including endogenous interaction terms. Discussion paper No. 2014-3, LeBow College of Business, Drexel University.

Card, D. (1995). Using Geographic Variation in College Proximity to Estimate the Return to Schooling. In Aspects of Labour Economics: Essays in Honour of John Vanderkamp, edited by Louis Christofides, E. Kenneth Grant and Robert Swindinsky. University of Toronto Press.

Chiswick, B. R. and P.W. Miller (2009). “The international transferability of immigrants' human capital”. Economics and Education Review, 28: 162-169.

Cobb-Clark, D. (2001). “The longitudinal survey of immigrants to Australia”. Australian Economic Review, 34(4): 467-477.

Docquier, F., Ozden, Ç., and G. Peri (2013). “The labour market effects of immigration and emigration in OECD Countries”. The Economic Journal, 124(579): 1106-1145.

Dolton, P., and A. Vignoles (2000). "The incidence and effects of overeducation in the U.K. graduate labour market”. Economics of Education Review, 19: 179-198.

Dustmann, C., and F. Fabbri (2003). "Language proficiency and labour market performance of immigrants in the UK”. The Economic Journal, 113(489): 695-717.

Eichhorst, W., Rodrigues-Planas, N., Schmidl, R., and K.F. Zimmermann (2013). A roadmap of vocational education and training around the world. IZA Discussion paper series No. 7110.

Farber, H.S., and R. Gibbons (1996). “Learning and Wage Dynamics”. Quarterly Journal of Economics, CXI: 1007-1047.

Ferrer, A. and W. Riddell (2008). "Education, Credentials and Immigrant Earnings". The Canadian Journal of Economics, 41: 186-216.

Green, C., P. Kler, and G. Leeves (2007). "Immigrant overeducation: Evidence from recent arrivals to Australia”. Economics of Education Review, 26(4): 420-432. 
Hausman, J.A., and W.E. Taylor (1981). "Panel data and unobservable individual effects.” Econometrica: 1377-1398.

Ioannides, Y. M., and Loury, L. D. (2004). "Job information networks, neighborhood effects, and inequality”. Journal of Economic Literature: 1056-1093.

Lange, F. (2007). “The speed of employer learning”. Journal of Labor Economics, 25(1): 135.

Lundberg, S.J., and R. Startz, (1983). "Private discrimination and social intervention in competitive labor market”. The American Economic Review, 73(3): 340-347.

Mansour, H. (2012). “Does employer learning vary by occupation?”. Journal of Labor Economics, 30(2): 415-444.

McKenzie, D. and Rapoport, H. (2010). "Self-Selection Patterns in Mexico-U.S. Migration: The Role of Migration Networks”. Review of Economics and Statistics, 92(4): 811.821.

Montgomery, J. D. (1991). "Social networks and labor-market outcomes: Toward an economic analysis”. The American Economic Review: 1408-1418.

Munshi, K. (2003). "Networks in the modern economy: Mexican migrants in the US labor market”. The Quarterly Journal of Economics: 549-599.

Oettinger, G.S. (1996). "Statistical discrimination and the early career evolution of the blackwhite wage gap”. Journal of Labor Economics, 14(1): 52-78.

Phelps, E.S. (1972). “The statistical theory of racism and sexism”. The American Economic Review, 62(4): 659-661.

Piracha, M., Tani, M. and M. Vaira (2014). “'Social capital and immigrants' labour market performance”, Papers in Regional Science (forthcoming)

Poot, J., and S. Stillman (2010). The importance of heterogeneity when examining immigrant education-occupation mismatch: evidence from New Zealand. IZA Discussion paper series No. 5211.

Rumberger, R.W. (1987). „The impact of surplus schooling on productivity and earnings”. Journal of Human Resources, 22(1): 24-50.

Sicherman, N. (1991). “Overeducation’ in the labour market”. Journal of Labour Economics, 9(2): 101-122.

Siniver, E. (2011). "Testing for statistical discrimination: The case of immigrant physicians in Israel”. Labour, 25(2): 155-166.

Verdugo, R.R., and N.T. Verdugo (1989). "The impact of surplus schooling on earnings: Some additional findings”. Journal of Human Resources, 24(4): 629-643. 
Wald, S., and T. Fang (2008). "Overeducated immigrants in the Canadian labour market: Evidence from the workplace and employee survey”. Canadian Public Policy, 34(4): 457479.

Wang, S.Y (2015). "Statistical discrimination, productivity and the height of immigrants". Industrial and Labor Relations Review (forthcoming).

Wooldridge, J.M. (2001). Econometric Analysis of Cross-Section and Panel Data, Cambridge: MIT Press.

Wooldridge, J.M. (2011). Endogenous interaction terms in 2SLS (Stata forum: http://www.stata.com/statalist/archive/2011-03/msg00188.html). Accessed 14 December 2014. 
Figure 1: Assessment of foreign qualifications: uptake rates by region of education

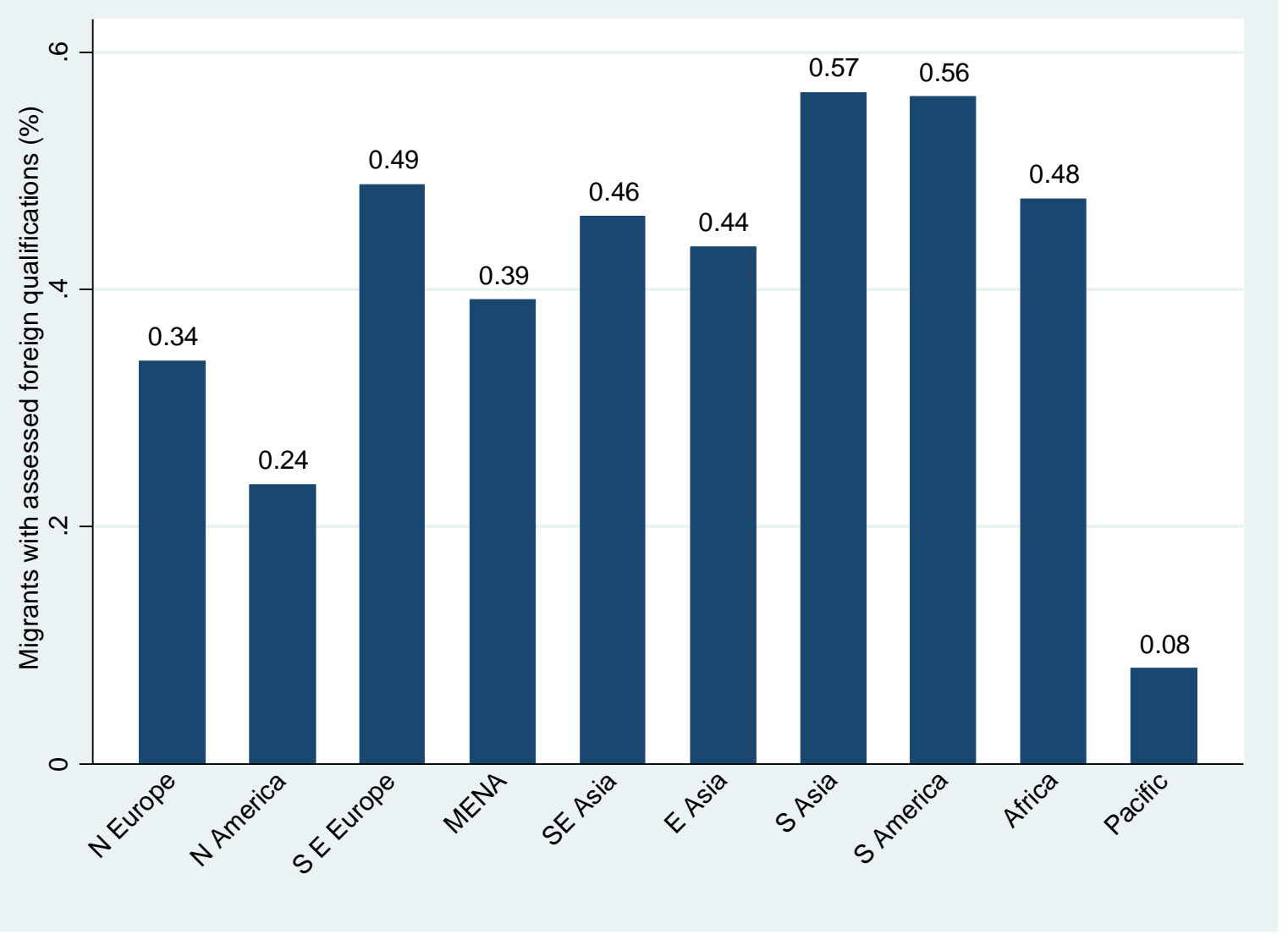

Source: cohort 1, LSIA 1 and cohort 1, LSIA 2. 
Figure 2: Unconditional distribution of log wages by region of education and assessment status
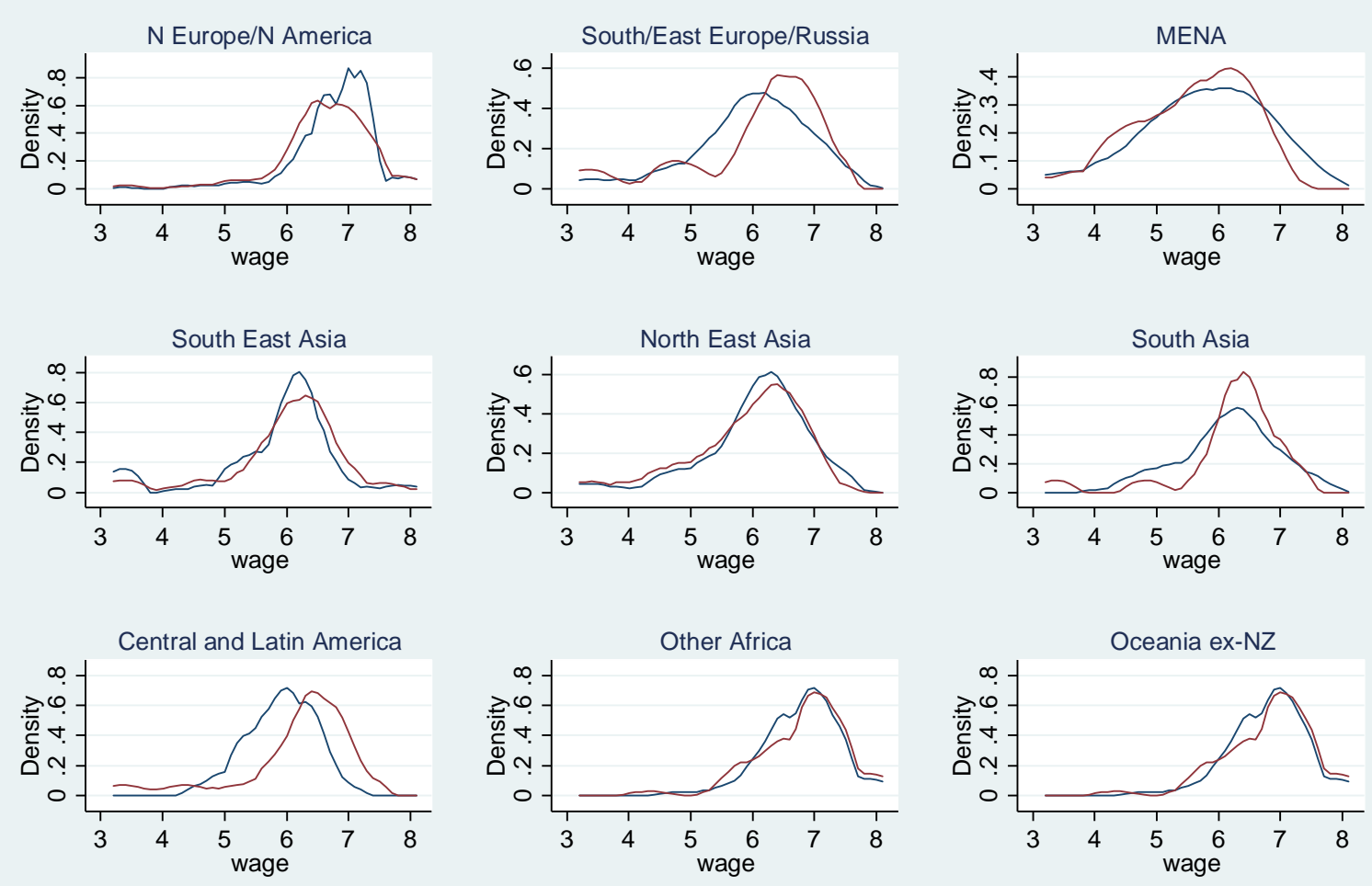

Qualifications not assessed

Qualifications assessed

Source: working sample, LSIA. 
Table 1: Baseline sample trimming - wave 1

\begin{tabular}{lcc}
\hline Baseline analysis & LSIA 1 & LSIA 2 \\
\hline Primary applicants $1^{\text {st }}$ wave, and & 5,201 & 3,124 \\
are aged 20-65 & 4,930 & 2,808 \\
migrated 1993-1995 or 1999-2000 & 4,927 & 2,805 \\
have tertiary education & 1,978 & 1,156 \\
enter labour market by $1^{\text {st }}$ wave & 1,408 & 842 \\
have wage & 880 & 684 \\
have employee status & 830 & 651 \\
have hours & 785 & 647 \\
have GDP information & 770 & 639 \\
Have network information & 760 & 635 \\
Have Gini information & 752 & 631 \\
\hline Observations used in the baseline analysis & \multicolumn{2}{c}{1,383} \\
\hline
\end{tabular}


Table 2: Baseline working sample - Primary applicant aged 20-65. First wave only

\begin{tabular}{|c|c|c|c|c|c|c|}
\hline & \multicolumn{2}{|c|}{ Qualification Assessed } & \multicolumn{2}{|c|}{$\begin{array}{c}\text { Qualification Not } \\
\text { Assessed }\end{array}$} & \multirow[t]{2}{*}{ Difference } & \multirow[t]{2}{*}{ t-stat } \\
\hline & Mean & Std & Mean & Std & & \\
\hline \multicolumn{7}{|l|}{ Key variables: } \\
\hline Ln weekly wage & 6.459 & .740 & 6.497 & .764 & $-.052 *$ & .0860 \\
\hline Instrument (raw) & 546.2 & 833.8 & 253.3 & 590.6 & $292.9 * * *$ & .0001 \\
\hline Instrument (dummy) & .554 & .498 & .266 & .442 & $.288 * * *$ & .0001 \\
\hline \multicolumn{7}{|l|}{ Country of education } \\
\hline English as main language & .666 & .472 & .739 & .439 & $-.073^{* *}$ & .0246 \\
\hline Log GDP per capita & 8.379 & 1.552 & 9.232 & 1.371 & $-.0853 * * *$ & .0001 \\
\hline N Europe/N America+ & .357 & .480 & .446 & .497 & $-.089 * * *$ & .0060 \\
\hline Asia & .289 & .454 & .359 & .480 & $-.070 * *$ & .0316 \\
\hline Rest of the world & .353 & .478 & .195 & .396 & $.158 * * *$ & .0001 \\
\hline \multicolumn{7}{|l|}{ Country of birth } \\
\hline English as main language & .630 & .483 & .625 & .484 & .005 & .8579 \\
\hline Commonwealth member & .494 & .501 & .490 & .500 & .004 & .8908 \\
\hline Network in host country++ & .050 & .084 & .053 & .087 & -003 & .8650 \\
\hline Gini++ + & .399 & .099 & .389 & .087 & .010 & .3932 \\
\hline \multicolumn{7}{|l|}{ Demographics } \\
\hline Age & 33.1 & 6.20 & 32.9 & 7.06 & .200 & 1731 \\
\hline Female & .315 & .465 & .367 & .482 & -.052 & .1120 \\
\hline Married & .573 & .495 & .622 & .485 & -.049 & .1341 \\
\hline Has resident children & .589 & .930 & .479 & .857 & $.110^{*}$ & .0607 \\
\hline Experience & 11.98 & 6.02 & 11.60 & 6.81 & $.038 * *$ & .0336 \\
\hline Interview in English & .970 & .170 & .965 & .184 & .005 & .8648 \\
\hline \multicolumn{7}{|l|}{ Labour market } \\
\hline Self-employed & .023 & .151 & .022 & .147 & .001 & .9671 \\
\hline Part-time & .139 & .347 & .139 & .346 & -.000 & .9920 \\
\hline Mills ratio (employed) & 6.562 & .341 & 6.597 & .425 & -.035 & .3268 \\
\hline \multicolumn{7}{|c|}{ Endogenous labour market controls } \\
\hline Occupation: Manager+ & .681 & .466 & .725 & .447 & .044 & .1739 \\
\hline Professional & .156 & .364 & .147 & .354 & .009 & .7790 \\
\hline Other & .163 & .370 & .127 & .333 & .036 & .2807 \\
\hline Licensed occupation & .395 & .489 & .350 & .477 & .045 & .1712 \\
\hline Over-qualified pre-migr.++ & .186 & .389 & .218 & .413 & -.032 & .3473 \\
\hline \multicolumn{7}{|l|}{ Migration visa } \\
\hline Family reunification+ & .089 & .285 & .313 & .464 & $-.224 * * *$ & .0001 \\
\hline Family sponsored & .277 & .448 & .122 & .327 & $.155^{* * *}$ & .0001 \\
\hline Employer nomination & .125 & .331 & .310 & .462 & $-.185 * * *$ & .0001 \\
\hline Skilled independent & .503 & .500 & .248 & .432 & $.255^{* * *}$ & .0001 \\
\hline Humanitarian & .006 & .079 & .006 & .080 & .000 & .1501 \\
\hline \multicolumn{7}{|l|}{ Other controls } \\
\hline LSIA1 (cohort 1) & .440 & .497 & .464 & .499 & -.024 & .4435 \\
\hline Lives in NSW, ACT+ & .490 & .500 & .479 & .500 & .011 & .7285 \\
\hline VIC, SA, TAS & .291 & .455 & .279 & .444 & .012 & .6995 \\
\hline QLS, WA, NT & .218 & .413 & .242 & .428 & -.024 & .4635 \\
\hline $\mathbf{N}$ & & & & & & \\
\hline
\end{tabular}

Source: LSIA 1 and LSIA 2. Number of observations: 752 (LSIA1) and 631 (LSIA2), respectively. The symbol + indicates the reference group of a categorical variable. The symbol ++ indicates a lower number of observations for that variable. The symbols *,**,*** indicate statistical significance at $10 \%, 5 \%$, and $1 \%$, respectively. 
Table 3: Baseline sample characteristics - Primary applicant aged 20-65

\begin{tabular}{|c|c|c|c|c|c|}
\hline & \multicolumn{3}{|c|}{ Cohort 1} & \multicolumn{2}{|c|}{ Cohort 2} \\
\hline & Wave 1 & Wave 2 & Wave 3 & Wave 1 & Wave 2 \\
\hline Initial sample & 1,978 & 1,695 & 1,402 & 1,156 & 957 \\
\hline Attrition rate & & $14.3 \%$ & $17.3 \%$ & & $17.2 \%$ \\
\hline \multicolumn{6}{|c|}{ Attrition on qualification status } \\
\hline $\begin{array}{l}\text { Completed } \\
\text { assessment }\end{array}$ & 328 & 285 & 246 & 224 & 190 \\
\hline Attrition rate & & $13.1 \%$ & $13.7 \%$ & & $15.1 \%$ \\
\hline
\end{tabular}


Table 4 - baseline first stage regression - $1^{\text {st }}$ wave LSIA, aged 20-65

\begin{tabular}{|c|c|}
\hline Qualification assessed & OLS \\
\hline Instrument: relative rank & $\begin{array}{c}.288 * * * \\
(.038)\end{array}$ \\
\hline Education completed in: Asia & $\begin{array}{c}-.205^{* * *} \\
(.072)\end{array}$ \\
\hline Rest of the world & $\begin{array}{c}-.395 * * * \\
(.059)\end{array}$ \\
\hline Country of education: English speaking & $\begin{array}{c}-.127 * * * \\
(.052)\end{array}$ \\
\hline Country of education: log GDP per capita & $\begin{array}{c}-.031^{* *} \\
(.014)\end{array}$ \\
\hline Female & $\begin{array}{l}.007 \\
(.028)\end{array}$ \\
\hline Married & $\begin{array}{l}-.008 \\
(.027)\end{array}$ \\
\hline Experience & $\begin{array}{c}.031 * * * \\
(.010)\end{array}$ \\
\hline Experience square & $\begin{array}{c}-.0006^{* *} \\
(.0002)\end{array}$ \\
\hline Has children at home & $\begin{array}{c}.010 \\
(.015)\end{array}$ \\
\hline Migration interview in English & $\begin{array}{l}.147 * * \\
(.067)\end{array}$ \\
\hline Country of birth: Commonwealth member state & $\begin{array}{c}.100 * * * \\
(.037)\end{array}$ \\
\hline Country of birth: English speaking & $\begin{array}{c}-.150^{* *} \\
(.041)\end{array}$ \\
\hline Country of birth: migrant network in host country & $\begin{array}{l}.038 \\
(.167)\end{array}$ \\
\hline Country of birth: income inequality (Gini coefficient) & $\begin{array}{l}.359 * * \\
(.152)\end{array}$ \\
\hline Cohort & $\begin{array}{l}.007 \\
(.047)\end{array}$ \\
\hline Visa: Concessional family & $\begin{array}{l}.291 * * \\
(.113)\end{array}$ \\
\hline Business nomination & $\begin{array}{l}.105 \\
(.106)\end{array}$ \\
\hline Skilled independent & $\begin{array}{c}.438^{* * * *} \\
(.099)\end{array}$ \\
\hline Humanitarian & $\begin{array}{c}.379 \\
(.431)\end{array}$ \\
\hline Self-employed & $\begin{array}{c}.066 \\
(.074)\end{array}$ \\
\hline Work part-time & $\begin{array}{l}-.002 \\
(.034)\end{array}$ \\
\hline Residence: Victoria, Tasmania and S Australia & $\begin{array}{l}.055 * * \\
(.026)\end{array}$ \\
\hline Queensland, N Territory, W Australia & $\begin{array}{l}.007 \\
(.029)\end{array}$ \\
\hline Constant & $\begin{array}{l}-.250 \\
(.468)\end{array}$ \\
\hline
\end{tabular}




\section{Other controls:}

Asia $\mathrm{x}$ age 28-32

Asia $\mathrm{x}$ age 33-39

Asia $\mathrm{x}$ age $40-65$

Rest of world x age 28-32

Rest of world $\mathrm{x}$ age 33-39

Rest of world $\mathrm{x}$ age $40-65$

Inverse Mills ratio (selection into employment)

Age group (3)

Visa x cohort

Yes

$\mathrm{N}$

$\mathrm{R}^{2}$

1,383

F-test

Source: $1^{\text {st }}$ wave LSIA 1 and LSIA 2. Estimates obtained by OLS in the first stage of 2SLS estimation using the Stata command ivreg2. The dependent variable is binary and equal to 1 if migrant has undertaken the assessment and zero otherwise. 
Table 5: Effect of the qualification on wages - Baseline OLS and 2SLS

\begin{tabular}{lcccc}
\hline & OLS & OLS & 2SLS & 2SLS \\
\hline Qualification assessed & .023 & .033 & $.302^{*}$ & $.387^{* *}$ \\
& $(.034)$ & $(.033)$ & $(.170)$ & $(.169)$ \\
Country of education: Asia & $-.142^{* * *}$ & $-.108^{* * *}$ & -.068 & -.014 \\
& $(.049)$ & $(.048)$ & $(.065)$ & $(.065)$ \\
& & & & \\
Country of education: RoW & $-.269^{* * *}$ & $-.204^{* * *}$ & $-.221^{* * *}$ & $-.142^{* *}$ \\
& $(.060)$ & $(.062)$ & $(.065)$ & $(.065)$ \\
& & & & \\
Constant & $3.089^{* * *}$ & $4.101^{* * *}$ & $2.998^{* * *}$ & $4.015^{* * *}$ \\
& $(.619)$ & $(.630)$ & $(.602)$ & $(.605)$ \\
\hline Controls: & & & & \\
Country education & Yes & Yes & Yes & Yes \\
Country birth & Yes & Yes & Yes & Yes \\
Visa type $x$ cohort & Yes & Yes & Yes & Yes \\
Demographics & Yes & Yes & Yes & Yes \\
State and labour market & Yes & Yes & Yes & Yes \\
Occupational fixed effects & No & Yes & No & Yes \\
\hline F-test $1^{\text {st }}$ stage & & & 58.62 & 58.05 \\
Endogeneity test (p-value) & & .5595 & .0874 & .0262 \\
$\mathrm{R}^{2}$ & .5311 & 1,383 & 1,383 & .5229 \\
$\mathrm{~N}$ & 1,383 & . & & 1,383 \\
\hline
\end{tabular}

Source: LSIA1 and LSIA 2. Estimates obtained by OLS (robust standard errors) and 2SLS, respectively. The dummy representing the assessment of foreign qualifications is treated as an endogenous regressor. Education: separate dummy variables for North Europe and North America (reference group), Asia (South East/East/South Asia) and the Rest of the World (Eastern Europe and Russia, MENA/Africa/Latin America). Country of birth: dummy variable if English is main language, dummy variable if member of the Commonwealth, share of migrants in Australia, income inequality (Gini coefficient). Cohort: dummy variable for LSIA 2. Visa: separate dummy variables for concessional family, business nomination, skilled independent, and humanitarian visa categories and their interaction with cohort. Demographics: gender, marital status, if there are resident children, if survey interview carried out in English, state of residence. Employment: experience and its square, dummy variable if working less than 35 hours per week, dummy variable if self-employed, selection into employment. Endogenous labour market covariates: occupational fixed effects (managers, the reference group; professionals; other). The $1^{\text {st }}$ stage F-test is the Angrist-Pischke multivariate F-test of excluded restrictions and tests the null hypothesis that the excluded instrument is correlated with the error term (the endogenous regressor is unidentified). In the case of a single endogenous regressor the AP also tests the null hypothesis that the instrument is only weakly correlated with the endogenous regressor. The endogeneity test is constructed as the difference between two Sargan-Hansen statistics and tests the null hypothesis that the endogenous regressor can be treated as an exogenous variable: only the $\mathrm{p}$-value of the test is reported. $\mathrm{R}^{2}$ reports the adjusted $\mathrm{R}^{2}$ in the case of OLS and the centred $\mathrm{R}^{2}$ in the case of 2SLS, respectively. Estimation performed using Stata command ivreg2. 
Table 6: Effect of the qualification on wages by incremental controls - Baseline 2SLS

\begin{tabular}{lccccccc}
\hline & I & II & III & IV & V & VI & VII \\
\hline Qualifications & $.272^{*}$ & $.496^{* *}$ & $.478^{* *}$ & $.449^{* *}$ & $.302^{*}$ & $.387^{* *}$ & $.383^{* *}$ \\
assessed $\widetilde{D}_{i j}$ & $(.150)$ & $(.241)$ & $(.235)$ & $(.204)$ & $(.170)$ & $(.169)$ & $(.173)$ \\
& & & & & & & \\
Controls & & & & & & & \\
Country education dummy & Yes & Yes & Yes & Yes & Yes & Yes & Yes \\
Country education other & No & Yes & Yes & Yes & Yes & Yes & Yes \\
Country birth & No & No & Yes & Yes & Yes & Yes & Yes \\
Visa type x cohort & No & No & No & Yes & Yes & Yes & Yes \\
Demographics & No & No & No & No & Yes & Yes & Yes \\
Labour market & No & No & No & No & Yes & Yes & Yes \\
Occupational fixed effects & No & No & No & No & No & Yes & Yes \\
Over-qualified pre-migr. & No & No & No & No & No & No & Yes \\
& & & & & & & \\
F-test & 113.54 & 45.87 & 47.27 & 65.02 & 58.62 & 58.05 & 52.78 \\
$\mathrm{R}^{2}$ & .0948 & .0709 & .0912 & .2161 & .5013 & .5229 & .5277 \\
$\mathrm{~N}$ & 1,383 & 1,383 & 1,383 & 1,383 & 1,383 & 1,383 & 1,252 \\
\hline
\end{tabular}

Source: LSIA1 and LSIA 2. Estimates obtained by 2SLS. The dummy representing the assessment of foreign qualifications is treated as an endogenous regressor. Control variables include: Education: separate dummy variables for North Europe and North America (reference group), Asia (South East/East/South Asia) and the Rest of the World (Eastern Europe and Russia, MENA/Africa/Latin America). Country of birth: dummy variable if English is main language, dummy variable if member of the Commonwealth, share of migrants in Australia, income inequality (Gini coefficient). Cohort: dummy variable for LSIA 2. Visa: separate dummy variables for concessional family, business nomination, skilled independent, and humanitarian visa categories and their interaction with cohort. Demographics: gender, marital status, if there are resident children, if survey interview carried out in English, state of residence. Employment: experience and its square, dummy variable if working less than 35 hours per week, dummy variable if self-employed, selection into employment. Endogenous labour market covariates: occupational fixed effects (managers, the reference group; professionals; other), dummy variable if over-qualified in last job prior to migrating. 
Table 7: Heterogeneity based on baseline 2SLS estimator without occupational fixed effects

\begin{tabular}{|c|c|c|c|c|c|c|c|c|c|c|c|}
\hline & \multicolumn{2}{|c|}{ Gender } & \multicolumn{4}{|c|}{ Pre-migration } & \multicolumn{2}{|l|}{ Cohort } & \multicolumn{3}{|c|}{ Job in Australia } \\
\hline & Male & Female & Cwth & Not Cwth & Not Lic. & Licensed & LSIA1 & LSIA2 & Full-time & Not Lic. & Licensed \\
\hline Qualification & .271 & $.515^{*}$ & $.315^{*}$ & -.086 & $.490 * *$ & .129 & .017 & $.528 * *$ & $.352 * *$ & .249 & .243 \\
\hline assessed & $(.213)$ & $(.311)$ & $(.175)$ & $(.502)$ & $(.234)$ & $(.246)$ & $(.221)$ & $(.257)$ & $(.160)$ & $(.212)$ & $(.240)$ \\
\hline Educated in & $-.144^{* *}$ & .111 & -.083 & -.127 & -.047 & -.083 & -.022 & -.141 & -.085 & -.096 & -.125 \\
\hline Asia & $(.073)$ & $(.136)$ & $(.081)$ & $(.126)$ & $(.079)$ & $(.107)$ & $(.079)$ & $(.103)$ & $(.061)$ & $(.067)$ & $(.110)$ \\
\hline Educated in & $-.298 * * *$ & -.101 & $-.286 * * *$ & $-.232 * *$ & $-.277 * * *$ & -.142 & -.106 & $-.367 * * *$ & $-.265 * * *$ & $-.311 * * *$ & $-.249 * *$ \\
\hline Row & $(.079)$ & $(.116)$ & $(.092)$ & $(.107)$ & $(.085)$ & $(.104)$ & $(.077)$ & (.109) & $(.063)$ & $(.062)$ & $(.115)$ \\
\hline Constant & $2.463 * * *$ & $3.905 * * *$ & $3.663 * * *$ & $3.557 * * *$ & $3.279 * * *$ & $1.774 * * *$ & $2.829 * * *$ & $3.589 * * *$ & $2.792 * * *$ & $2.914 * * *$ & $2.252 * * *$ \\
\hline & $(.730)$ & $(1.081)$ & $(1.294)$ & $(.878)$ & $(.864)$ & $(.997)$ & $(.754)$ & $(.997)$ & $(.601)$ & $(.721)$ & $(1.036)$ \\
\hline F-test $1^{\text {st }}$ stage & 34.63 & 19.58 & 44.24 & 7.47 & 30.95 & 26.79 & 26.76 & 33.16 & 54.11 & 28.40 & 24.09 \\
\hline Endogeneity test & .2226 & .0920 & .0983 & .9153 & .0592 & .2726 & .9064 & .0506 & .0445 & .3553 & .2535 \\
\hline $\mathrm{R}^{2}$ & .4815 & .5032 & .4317 & .5461 & .5092 & .5290 & .5534 & .4749 & .2814 & .3428 & .2963 \\
\hline $\mathrm{N}$ & 900 & 483 & 680 & 703 & 697 & 558 & 752 & 631 & 1,190 & 720 & 443 \\
\hline
\end{tabular}

Source: LSIA1 and LSIA 2. Estimates obtained by 2SLS instrumenting the assessment of foreign qualifications with country of birth. The dependent variable is the logarithm of weekly wages, calculated as the midpoint of the relevant intervals. The highest wage (unbounded interval) is calculated as 1.4 times the lower bound of the corresponding interval. The dummy representing the assessment of foreign qualifications is treated as an endogenous regressor. Education: separate dummy variables for North Europe and North America (reference group), Asia (South East/East/South Asia) and the Rest of the World (Eastern Europe and Russia, MENA/Africa/Latin America). Each of these is interacted with age groups 28-32; 33-39, and 40-65, respectively. Country of birth: dummy variable if English is main language, dummy variable if member of the Commonwealth, share of migrants in Australia, income inequality (Gini coefficient). Cohort: dummy variable for LSIA 2. Visa: separate dummy variables for concessional family, business nomination, skilled independent, and humanitarian visa categories and their interaction with cohort. Demographics: gender, marital status, if there are resident children, if survey interview carried out in English, state of residence. Employment: experience and its square, dummy variable if working less than 35 hours per week, dummy variable if self-employed, selection into employment. Endogenous labour market covariates: occupational fixed effects (managers, the reference group; professionals; other), dummy variable if over-qualified in last job prior to migrating. The $1^{\text {st }}$ stage F-test is the Angrist-Pischke multivariate F-test of excluded restrictions and tests the null hypothesis that the excluded instrument is correlated with the error term (the endogenous regressor is unidentified). In the case of a single endogenous regressor the AP also tests the null hypothesis that the instrument is only weakly correlated with the endogenous regressor. The endogeneity test is constructed as the difference between two Sargan-Hansen statistics and tests the null hypothesis that the endogenous regressor can be treated as an exogenous variable: only the p-value of the test is reported. $\mathrm{R}^{2}$ reports the centred $\mathrm{R}^{2}$ in the case of 2SLS. Estimation performed using Stata command ivreg2. Full-time excludes self-employment. Not licensed and licensed apply to salaried full-time jobs only. 
Table 8 - Wage penalty over time. Panel Random Effects estimator. Same employer.

\begin{tabular}{lccc}
\hline & Random Effects & $\begin{array}{c}\text { Random Effects } \\
\text { (Baltagi) }\end{array}$ & Hausman-Taylor \\
\hline $\begin{array}{l}\text { Qualification } \\
\text { assessed }\end{array}$ & $.387^{*}$ & $.507^{* * *}$ & $.467^{* * *}$ \\
Qualification & $.057^{* *}$ & $(.162)$ & $(.175)$ \\
assessed x time & $(.026)$ & $.056^{* *}$ & $.057^{* *}$ \\
Educated in Asia & $-.130^{*}$ & $(.026)$ & $(.026)$ \\
& $(.077)$ & -.097 & -.105 \\
Educated in RoW & $-.370^{* * *}$ & $(.069)$ & $(.070)$ \\
& $(.081)$ & $-.345^{* * *}$ & $-.350^{* * *}$ \\
Educated in Asia $\mathrm{x}$ & .015 & $(.078)$ & $(.080)$ \\
Time & $(.013)$ & .015 & .015 \\
Educated in RoW x & .013 & $(.013)$ & $(.013)$ \\
Time & $(.016)$ & .013 & .013 \\
Constant & & $(.016)$ & $(.016)$ \\
& $5.333^{* * *}$ & & $5.237^{* * *}$ \\
& $(.339)$ & $5.203^{* * *}$ & $(.337)$ \\
\hline $\mathrm{R}^{2}$ within & .2607 & $(.310)$ & \\
$\mathrm{R}^{2}$ between & .4660 & .2612 & $1,145.75$ \\
$\mathrm{R}^{2}$ overall & .4052 & .4308 & 2,084 \\
Wald-Chi & $1,163.96$ & .3731 & \\
$\mathrm{~N}$ & 2,084 & $1,136.88$ & \\
\hline So & 2,084 & \\
\hline
\end{tabular}

Source: LSIA 1 and LSIA 2. Education: separate dummy variables for North Europe and North America (reference group), Asia (South East/East/South Asia) and the Rest of the World (Eastern Europe and Russia, MENA/Africa/Latin America). Country of birth: dummy variable if English is main language, dummy variable if member of the Commonwealth, share of migrants in Australia, income inequality (Gini coefficient). Cohort: dummy variable for LSIA 2. Visa: separate dummy variables for concessional family, business nomination, skilled independent, and humanitarian visa categories and their interaction with cohort. Demographics: gender, marital status, if there are resident children, if survey interview carried out in English, state of residence. Employment: experience and its square, dummy variable if working less than 35 hours per week, dummy variable if self-employed, selection into employment in the first wave. The Hausman-Taylor model removes the assumption of orthogonality between the unobserved individual-specific random effect and some of the explanatory variables. In particular, the instrumented variable is only correlated with the unobserved individual heterogeneity and not with the idiosyncratic error term. The estimators implemented in xtivreg assume that some of the explanatory variables in the model are correlated with the idiosyncratic error. In contrast, the Hausman-Taylor estimator implemented in Stata command xthtaylor assume that some of the explanatory variables are correlated with the individual-level random effects, but that none of the explanatory variables are correlated with the idiosyncratic error. 
Table 9: Heterogeneity based on Hausman-Taylor estimator. Same employer unless otherwise specified.

\begin{tabular}{|c|c|c|c|c|c|c|c|c|}
\hline & $\begin{array}{c}\text { Occupational } \\
\text { FE }\end{array}$ & $\begin{array}{l}\text { All labour mkt } \\
\text { endog. controls }\end{array}$ & $\begin{array}{l}\text { All employers } \\
\text { pooled }\end{array}$ & Not Licensed & Licensed & $\begin{array}{c}\text { Born in } \\
\text { Commonwealth }\end{array}$ & Born elsewhere & $\begin{array}{c}\text { Non-English } \\
\text { Speakers }\end{array}$ \\
\hline Educated in Asia & $\begin{array}{l}-.084 \\
(.071)\end{array}$ & $\begin{array}{l}-.148^{*} \\
(.087)\end{array}$ & $\begin{array}{l}-.108 \\
(.268)\end{array}$ & $\begin{array}{l}-.115 \\
(.107)\end{array}$ & $\begin{array}{l}-.043 \\
(.111)\end{array}$ & $\begin{array}{l}-.131 \\
(.104)\end{array}$ & $\begin{array}{l}-.118 \\
(.105)\end{array}$ & $\begin{array}{l}-.120 \\
(.145)\end{array}$ \\
\hline $\begin{array}{l}\text { Educated in } \\
\text { RoW }\end{array}$ & $\begin{array}{c}-.280 * * * \\
(.082)\end{array}$ & $\begin{array}{c}-.324 * * * \\
(.103)\end{array}$ & $\begin{array}{l}-.322 \\
(.307)\end{array}$ & $\begin{array}{c}-.494 * * * \\
(.122)\end{array}$ & $\begin{array}{l}-.056 \\
(.142)\end{array}$ & $\begin{array}{c}-.305^{* *} \\
(.126)\end{array}$ & $\begin{array}{c}-.397 * * * \\
(.110)\end{array}$ & $\begin{array}{c}-.366 * * * \\
(.139)\end{array}$ \\
\hline $\begin{array}{l}\text { Educated in Asia } \\
\mathrm{x} \text { Time }\end{array}$ & $\begin{array}{c}.012 \\
(.013)\end{array}$ & $\begin{array}{c}.017 \\
(.012)\end{array}$ & $\begin{array}{c}.012 \\
(.011)\end{array}$ & $\begin{array}{c}.014 \\
(.018)\end{array}$ & $\begin{array}{c}.012 \\
(.017)\end{array}$ & $\begin{array}{c}.014 \\
(.013)\end{array}$ & $\begin{array}{l}-.008 \\
(.025)\end{array}$ & $\begin{array}{l}.014 \\
(.037)\end{array}$ \\
\hline $\begin{array}{l}\text { Educated in } \\
\text { RoW x Time }\end{array}$ & $\begin{array}{c}.007 \\
(.016)\end{array}$ & $\begin{array}{c}.023 \\
(.015)\end{array}$ & $\begin{array}{l}.014 \\
(.013)\end{array}$ & $\begin{array}{c}.017 \\
(.019)\end{array}$ & $\begin{array}{l}-.024 \\
(.028)\end{array}$ & $\begin{array}{l}.037^{*} \\
(.021)\end{array}$ & $\begin{array}{l}-.020 \\
(.025)\end{array}$ & $\begin{array}{l}-.019 \\
(.039)\end{array}$ \\
\hline
\end{tabular}

Source: LSIA 1 and LSIA 2. Control variables include: Education: separate dummy variables for North Europe and North America (reference group), Asia (South East/East/South Asia) and the Rest of the World (Eastern Europe and Russia, MENA/Africa/Latin America). Country of birth: dummy variable if English is main language, dummy variable if member of the Commonwealth, share of migrants in Australia, income inequality (Gini coefficient). Cohort: dummy variable for LSIA 2. Visa: separate dummy variables for concessional family, business nomination, skilled independent, and humanitarian visa categories and their interaction with cohort. Demographics: gender, marital status, if there are resident children, if survey interview carried out in English, state of residence. Employment: experience and its square, dummy variable if working less than 35 hours per week, dummy variable if self-employed, selection into employment at the time of the first wave. The Hausman-Taylor model removes the assumption of orthogonality between the unobserved individual-specific random effect and some of the explanatory variables. In particular, the instrumented variable is only correlated with the unobserved individual heterogeneity and not with the idiosyncratic error term. The estimators implemented in xtivreg assume that some of the explanatory variables in the model are correlated with the idiosyncratic error. In contrast, the Hausman-Taylor estimator implemented in Stata command xthtaylor assume that some of the explanatory variables are correlated with the individual-level random effects, but that none of the explanatory variables are correlated with the idiosyncratic error. 


\section{Appendix}

\section{A2. Tests of endogeneity}

Table A1 presents evidence of the endogeneity of undertaking the assessment. This is formally tested using the approach suggested by Wooldridge (2010 $)^{19}$ and the endogeneity test built in Stata's ivreg2 command ${ }^{20}$.

The tests support the endogeneity of the assessment choice variable and the positive selection of those undertaking it with respect to wages. Hence those choosing to add a local signal are more likely to earn higher wages, and vice-versa. Controlling for endogeneity with the instrument results in a negative and statistically significant effect of the local signal: undertaking the assessment is associated with substantially lower wages. This is prima facie contradictory as one would expect that a clearer signal of productivity is attractive to those who feel disadvantaged by a pooling equilibrium where host country employers cannot attribute a premium to education acquired abroad. The analysis of heterogeneity will shed light on the mechanisms at work.

\footnotetext{
${ }^{19}$ Wooldridge (2010 - eq.15.51 p.528) suggests estimating the wage equation (1) by OLS, augmented by the residual of the regression of the endogenous choice on all exogenous and instrumented variables. The choice of undertaking the assessment is deemed endogenous if the residual from the first stage regression is statistically significantly different from zero.

${ }^{20}$ Stata's ivreg2 command includes an endogeneity test that evaluates the difference between the Sargan-Hansen statistics for the equation where the suspect regressor is treated as endogenous and the corresponding statistics for the equation where the suspect regressors are treated as exogenous. The null hypothesis is that the suspected endogenous variable can in fact be treated as exogenous.
} 
Table A1: Endogeneity test (residuals $1^{\text {st }}$ stage) - Primary applicant aged 20 to 65

OLS residuals Endogeneity Test (2SLS)

\begin{tabular}{lcccc}
\hline Qualifications & $.302^{*}$ & $.387^{* *}$ & $.302^{*}$ & $.387^{* *}$ \\
assessed & $(.164)$ & $(.162)$ & $(.170)$ & $(.169)$ \\
& & & & \\
Residuals 1st stage & $-.291^{*}$ & $-.369 * *$ & & \\
& $(.165)$ & $(.162)$ & & \\
Endogeneity Test (p-value) & & & .0874 & .0262
\end{tabular}

\section{Controls:}

Education

Country of birth

Cohort

Cohort

Visa

Demographics

Employment

Occupational Fixed Effects

$\begin{array}{ll}\text { Y } & \text { Y } \\ \text { Y } & \text { Y } \\ \text { Y } & \text { Y } \\ \text { Y } & \text { Y } \\ \text { Y } & \text { Y } \\ \text { Y } & \text { Y } \\ \text { Y } & \text { Y } \\ \text { N } & \text { Y }\end{array}$

$\begin{array}{ll}\text { Y } & \text { Y } \\ Y & \text { Y } \\ Y & \text { Y } \\ Y & \text { Y } \\ Y & \text { Y } \\ \text { Y } & \text { Y } \\ \text { Y } & \text { Y } \\ \text { N } & \text { Y }\end{array}$

\begin{tabular}{lllll}
$\mathrm{R}^{2}$ & .5321 & .5611 & .5082 & .5229 \\
$\mathrm{~N}$ & 1,383 & 1,383 & 1,383 & 1,383 \\
\hline
\end{tabular}

Source: $1^{\text {st }}$ wave LSIA1 and LSIA2. Control variables include: Education: separate dummy variables for North Europe and North America (reference group), Asia (South East/East/South Asia) and the Rest of the World (Eastern Europe and Russia, MENA/Africa/Latin America). Country of birth: dummy variable if English is main language, dummy variable if member of the Commonwealth, share of migrants in Australia, income inequality (Gini coefficient). Cohort: dummy variable for LSIA 2. Visa: separate dummy variables for concessional family, business nomination, skilled independent, and humanitarian visa categories and their interaction with cohort. Demographics: gender, marital status, if there are resident children, if survey interview carried out in English, state of residence. Employment: experience and its square, dummy variable if working less than 35 hours per week, dummy variable if self-employed. Occupational Fixed Effects: the reference group is managerial occupations; two separate dummy variables for working as a professional, or in other professions, respectively. 
Figure A1: Unconditional distribution of log wages by region of education and assessment status using a different regional grouping
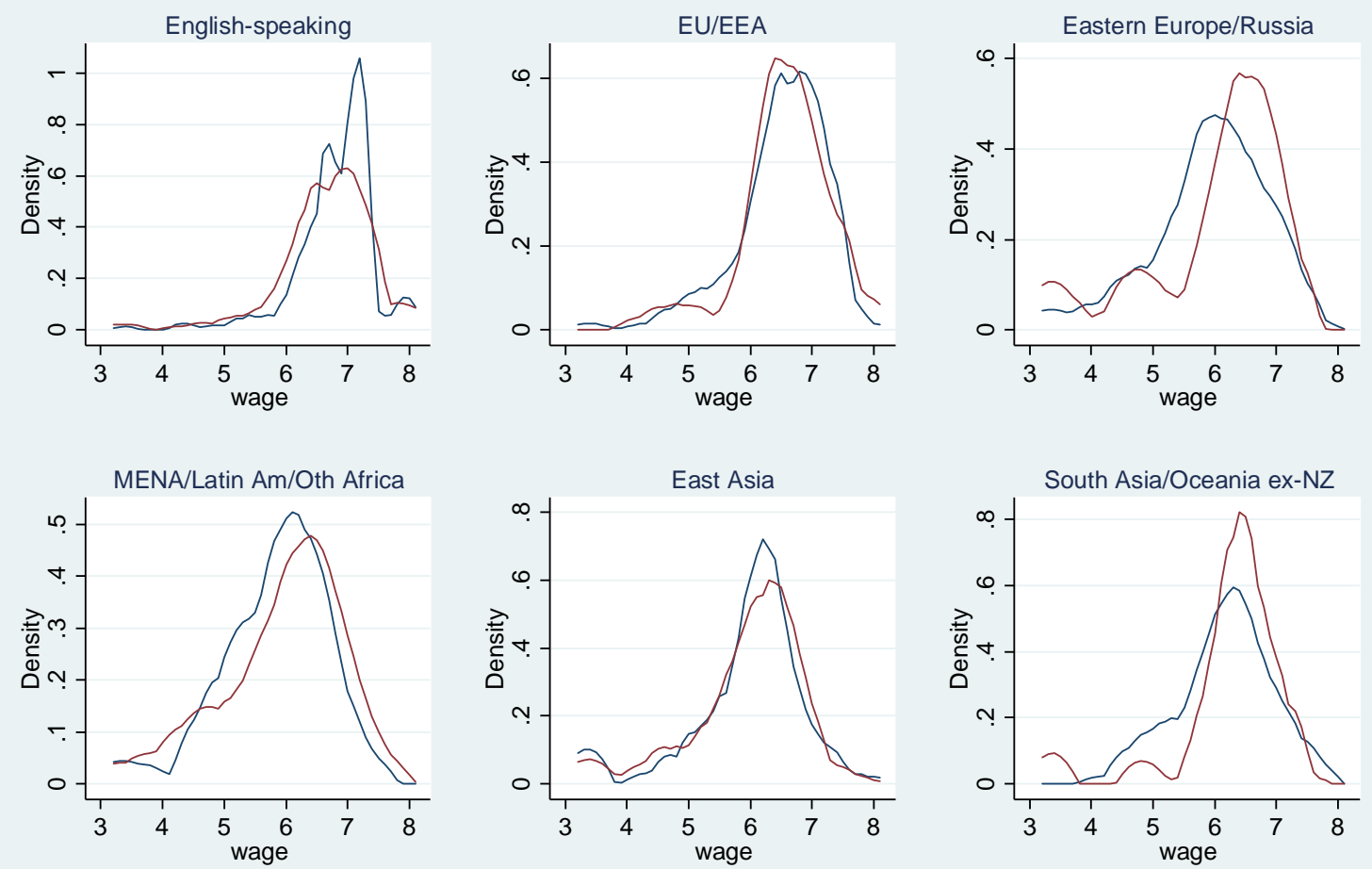

Qualifications not assessed

Qualifications assessed

Source: LSIA1 and LSIA 2. 
Figure A2: Unconditional distribution of log hourly wages by region of education and assessment status
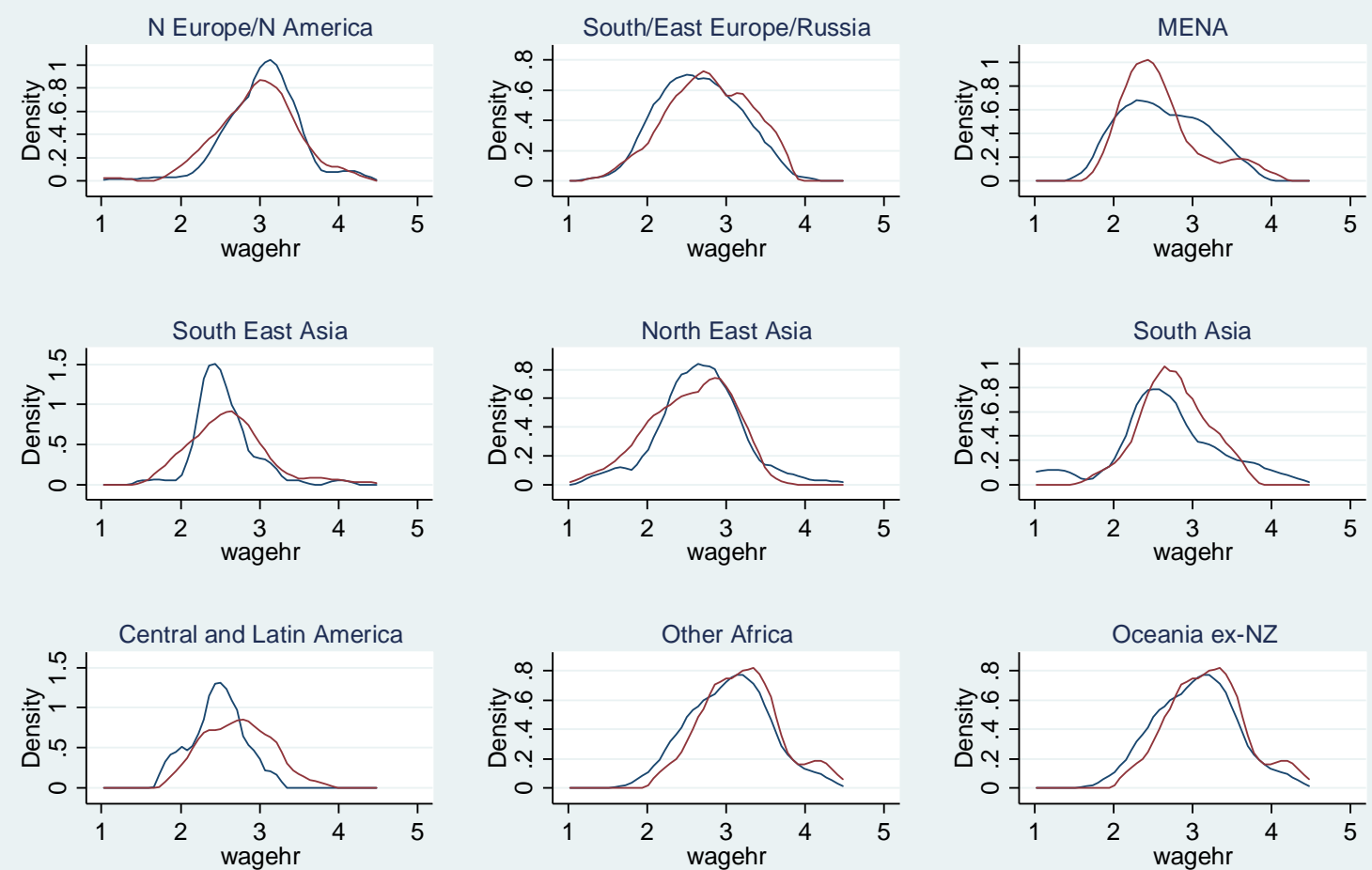

Qualifications not assessed

Qualifications assessed

Source: LSIA1 and LSIA2. 